\title{
Dynamics of China's Carbon Prices in the Pilot Trading Phase
}

\author{
John Hua Fan and Neda Todorova* \\ Department of Accounting, Finance and Economics \\ Griffith Business School \\ Griffith University
}

Forthcoming in Applied Energy

\begin{abstract}
This paper is the first to investigate empirically the link between carbon prices and macro risks in China's cap-and-trade pilot scheme. Using data from four pilot markets in Beijing, Guangdong, Hubei, and Shenzhen from 2014 to 2016, we demonstrate that the carbon price in Hubei is weakly linked to international prices of natural gas. Our results also indicate that energy, utilities, industrial and materials sector indices are positively related to the allowance prices in Shenzhen and Guangdong, suggesting that higher emitters in the region may have factored the carbon price into their production mix. We find no statistically significant relationship in the Beijing pilot. Overall, the findings suggest that China's carbon market is currently in an early stage of development, as the carbon price fundamentals are weak and the markets are comparatively less efficient than the European trading scheme in an informational sense. The findings of the paper have policy implications for the upcoming integration of regional markets into the national carbon market.
\end{abstract}

JEL Classification: G1, Q5

Keywords: Carbon Emissions; China; ETS; Energy; Financial Risks.

\footnotetext{
* Corresponding author. 170 Kessels Road, Nathan, Queensland 4111, Australia. Tel: +61 73735 7219; Fax: +61 73735 7760. E-mail: n.todorova@griffith.edu.au.

The authors wish to thank Alexandr Akimov, Robert Bianchi, David Broadstock, Adam Clements, Celeste Jiang, Tatsuyoshi Okimoto, Ron Ripple, Eduardo Roca, Xunpeng Shi, Stefan Trueck, Osei Waife, and participants at the Griffith Alternative Investments Conference held at Surfers Paradise in 2016, Gold Coast and the Australasian Commodity Markets Conference held at Macquarie University Sydney in 2017 for their helpful comments. Parts of the paper were completed while John Hua Fan was a visiting research scholar at the College of Environmental Sciences and Engineering, Peking University (PKU). We wish to acknowledge the mentorship by Shiqiu Zhang (PKU). We thank Climate-Connect for providing us with the carbon data. Funding support from the Griffith Asia Institute is gratefully acknowledged. An earlier version of the paper circulated under the title "Carbon Prices and Macroeconomic Risks in China: Evidence from the Pilot Trading Phase". All errors are our own.
} 


\section{Introduction}

For a considerable time following the introduction of the European Union's Emissions Trading Scheme (EU-ETS), China, the largest emitter of carbon dioxide $\left(\mathrm{CO}_{2}\right)$ by volume in the world, has been under international pressure to reduce its $\mathrm{CO}_{2}$ emissions. Subsequent to the United Nations Climate Change Conference (COP15) in Copenhagen in 2009, China's government announced its intention to cut carbon intensity or greenhouse gas (GHG) emissions per unit of gross domestic product (GDP) by 40 to 45 percent below 2005 levels by 2020. Despite challenges like its emerging economy, its developing financial market, and inadequate technology to facilitate practical carbon trading, China surprised the world by announcing a national emissions trading scheme (ETS) that would commence in the second half of 2017. If successful, China's ETS will become the world's largest, doubling the size of the EU-ETS (Reuters, 2014; Bloomberg, 2016). ${ }^{1}$ Less known to the world is that China has been experimenting with regional carbon market pilots since 2011. Currently, eight regional markets-Beijing, Shanghai, Tianjin, Shenzhen, Chongqing, Guangdong, Hubei, and Fujian-are operational.

While the literature on the EU-ETS carbon market is maturing, our understanding of the emerging carbon market in China is rather limited. China's commitment to capping its carbon emissions through 2030 highlights the urgency to understand the pricing of carbon and the effectiveness of the market mechanism that is already in place. This paper investigates the price behaviour of carbon emissions in mainland China and its links with macro-level financial risks (stock market and bond yield), energies and metals price dynamics (coal, steel, iron ore, LNG, gas, and oil), and the overall sentiment of China's market (CHVIX and OVX). ${ }^{2}$ The pricing of carbon allowances plays a critical role in the design of an ETS system, as a stable carbon price that gradually increases ensures the transition from a pollution-intensive economy to a cleaner, more sustainable economy in the long run. Consequently, the findings presented in this paper shed new light on the final

\footnotetext{
${ }^{1}$ Carbon emissions are central to the issue of global warning and are among the biggest challenges ever to face the world. The EU-ETS was launched in 2005 to address global warming. The EU-ETS is the largest multi-country, multi-sector mandatory greenhouse gas emissions trading regime ever devised. By tightening the supply of carbon allowances, the scheme forces emitters to invest in alternative energy technologies in the long term, thereby to achieve a gradual transition from a pollution-intensive industry sector to a cleaner, more sustainable industry sector. However, the EU-ETS is now in its tenth year of operation, and its effectiveness in achieving its goal of reducing carbon emissions is under debate (See Aldy and Stavins, 2012; Löfgren et al., 2014; The Telegraph, 2015).

${ }^{2}$ Daily natural gas and electricity prices in China are not available. Coal price series at daily frequency (China Foundry Coke domestic spot price Shanghai) tend to be stale.
} 
design of China's ETS (i.e. its allocation of allowances, cap pricing, industry coverage, and compliance issues).

Hintermann et al. (2016) provide a summary of the empirical literature on carbon allowance prices since phase II of the EU-ETS and highlight the roles of economic activity, growth announcements, and energy prices in the dynamics of the carbon prices in Europe. Aatola et al. (2013) document a negative influence of coal prices on the price of carbon, whereas Lutz et al. (2013) find a negative relationship only in certain periods. Earlier studies, such as Mansannet-Bataller et al. (2007) and Alberola et al. (2008), provide evidence that carbon prices in the EU-ETS are linked to oil, gas, and coal prices. In terms of economic activities, Chevallier $(2009,2011)$ show that there is a weak link between macro factors (equity dividend yield and junk bond premium) and carbon prices.

The literature on China's ETS is currently in its infancy. A limited number of studies focus on the policy debate rather than quantitative analysis of the allowance price. Zhang (2015) discusses the motivation behind implementing the ETS instead of a carbon tax policy. Liu et al. (2015) explore the policy process and barriers to the development of ETS, while Zhao et al. (2016) comment on the market efficiency of ETS pilots based on a naïve assessment of price, trading volume, and information transparency. These studies offer some first-hand lessons from early observations of China's carbon pilots, including the need to improve market liquidity, information transparency, and operational efficiency. A number of studies simulate the impact of various allowance-allocation strategies on the performance of a national trading system (Cong and Wei, 2010; Yuan et al., 2012, Tang and Wu, 2013, Zhang et al., 2016), finding that an ETS system improves economic efficiency and increases the price of electricity.

More recently, Ren and Lo (2017) find that the rate of return in the Shenzhen carbon market is negatively associated with expected risk, and Liu et al. (2017) study the impact of the policy mix on the operating national carbon emission trading market in China. Wu et al. (2017) assess emissions trading policy among sectors in the Shanghai pilot and find that trading behaviour depends on burden-sharing and the use of renewable energy. Xiong et al. (2017) conduct a comparative analysis of the designs of China's ETS with the EU-ETS and the California ETS in which they highlight distinctive features in allowance mechanisms that affect the efficiency of China's pilot markets. Motivated by these distinctions, we contribute to this emerging literature by investigating the deterministic drivers of carbonallowance prices across trading pilots in China. By employing pricing fundamentals that 
have been proven effective in the more mature and developed EU-ETS markets, we draw conclusions about the overall informational efficiency of China's carbon markets and provide policy implications for the upcoming integration of regional markets into the National Emissions Trading Scheme. ${ }^{3}$

The scarcity of empirical research on China's pilots may be due to the length of available data. Although data on price and trading volume are available from the respective exchanges, historical archives are not easily accessible. By employing a comprehensive dataset from all seven pilot exchanges, we provide the first deterministic analysis of carbon-allowance pricing in China's ETS. ${ }^{4}$ The main challenge in using the dataset is the large number of missing values that indicate little or no trading activity. In order to draw meaningful conclusions from the data and our analysis, we focus on four markets: Beijing, Guangdong, Hubei, and Shenzhen. ${ }^{5}$ We conduct regression analysis based on weekly returns series that are constructed using volume-weighed prices. Our findings suggest that the allowance price in the pilots' trading phase is only weakly linked to stock market and energy prices, although this finding is not universal across the four markets.

This paper makes three primary contributions to the carbon literature. First, after providing fresh insights into the institutional settings of each trading pilot, we investigate the explanatory power of macro-level financial risks. Oberndorfer (2009) and Veith et al. (2009) demonstrate that stock returns of the most affected companies (i.e. electricity) under the EU-ETS are positively correlated with carbon pries and conclude that firms can not only pass the regulatory burden on to customers but can also profit by overcompensating for the costs. We find that carbon prices in Hubei loads weakly on the utilities index and that the Shenzhen pilot prices exhibit a positive relationship with energy and materials sector indices, suggesting that high emitters in the region may have factored the carbon prices into their operations. However, we found no significant relationships in the Beijing or Guangdong pilots.

\footnotetext{
${ }^{3}$ For an overview of the literature, also refer to Jiang et al. (2016). For quantification and a driving-force analysis of provincial-level carbon emissions in China, see Ye et al. (2017).

${ }^{4}$ The Fujian trading pilot was launched on 30 September 2016. The first available data coincides with the end of the sample period.

${ }^{5}$ The large number of missing values in prices and volume, along with the relatively short sample period, preclude the application of more advanced models like GARCH, jump-diffusion, Markov-switching, and VAR-type models that have been employed in the EU-ETS literature. (See Benz and Truck, 2009; Chevallier 2011; Aatola et al., 2013; Lutz et al., 2013; Sanin et al., 2015.)
} 
Second, studies such as Mansannet-Bataller et al. (2007) and Alberola et al. (2008) provide evidence that carbon prices in the EU-ETS are linked to oil, gas, and coal prices, while Aatola et al. (2013) and Lutz et al. (2013) document a negative influence of coal prices on the price of carbon. Motivated by these findings, we investigate the relationship between the prices of carbon allowance with variations in the coal, steel, gas, and crude oil prices and the iron ore inventory. These variables are selected because China is the world's largest producer of steel, and its iron- and steel-production industries, which are largely stateowned, are more energy-intensive than those industries are in other developing countries, such as Brazil and Poland (Worrell et al., 1997). As a result, data on China's iron ore inventory and steel prices contain dynamics that are relevant to a variety of economic functions. In addition, we choose these variables because China's energy imports, fuelled by rapid economic expansion, have grown significantly over the past decade. To separate domestic shocks from regional and global shocks, we employ price series that reflect China's (coal, steel, and iron ore), Asia's (JCC, Asia LNG, and Australia coal) and global (Brent and NYMEX gas) demand and supply dynamics.

We find that Brent crude oil in both the Hubei and the Shenzhen pilots exhibits statistically significant relationship with the allowance prices. While the positive significance of crude oil in Hubei conforms to findings in the extant literature (Chevallier, 2009; Chevallier, 2011; Aatola et al., 2013; Lutz et al, 2013), the negative sign in Shenzhen is at odds with previous results and suggests that high (low) fuel prices contribute to the decrease (increase) in carbon prices and the possibility of omitted variables. Once again, no statistically significant relationship was found in Beijing and Guangdong pilots. The lack of association with established energy variables suggests that the pricing fundamentals of China's carbon market remain relatively weak, as variables that have been informative in the EU-ETS are not currently priced in China's trading pilots. The differences in Brent crude price loadings may also suggest that carbon price dynamics in Hubei and Shenzhen pilots differ.

Third, since our sample period overlaps with the recent meltdown in China's equity markets, we include sentiment variables as a way to determine how carbon prices in each 
pilot respond to expectations on the state of the economy, as reflected by the market trend. ${ }^{6}$ Following Prete and Norman (2013), we employ China's VIX (CHVIX) index from AlphaShares in which measures the implied volatility of options on China's equity indices with the most liquid derivatives markets. For robustness, we consider a second measure for sentiment, proxied by the inflow/outflow of CSOP Asset Management's China-related ETFs that have AUMs larger than CNY200m and the OVX index, which measures the market's expectations regarding 30-day volatility of crude oil prices to the US oil fund options, spanning a wide range of strike prices. We find that carbon prices in all pilots monotonically show no response to changes in market sentiment, suggesting that equitymarket volatility has minimal impact on the dynamics of China's carbon markets in the sample period.

We also conduct robustness tests in a multiple regression setting by including autoregressive terms, lagged carbon-market volatility, and a compliance dummy, all of which are specific to each pilot. We consider two systems, with the first focusing on China and regional dynamics and the second incorporating global energy price dynamics. We find that, after controlling for global energy prices, the Hubei pilot is positively correlated with NYMEX natural gas and negatively correlated with the JCC index. The positive association is consistent with the findings of Mansannet-Bataller et al. (2007) and Alberola et al. (2008), who find that an increase in energy prices signals an increase in energy demand and the increase in energy demand suggests an increase in the generation of carbon emissions, which should increase the demand for allowances.

The negative association with crude oil may seem counter-intuitive at first because an increase in oil prices reflects an increase in energy demand, which in turn leads to higher price of carbon allowances. alddynamics can be used to rationalise this unexpected finding. On the demand side of energy, China has experienced a prolonged period of slowdown in economic growth. As the growth rate (and even the level) of production declines, the demand for emissions also declines. (See Declercq et al., 2011.) This relationship is more pronounced when oil prices are high. On the supply side of energy, high crude oil prices

\footnotetext{
${ }^{6}$ From June 2015 to February 2016, China's equity markets exhibited erratic price movements which that considerable attention internationally. A third of the value of A shares on the Shanghai Stock Exchange was wiped out within one month. In July 2015, the Shanghai stock market fell 30 percent when 1,400 companies (more than half of those listed) filed for a trading halt in an attempt to prevent further losses. After three relatively stable weeks, the index fell again on 24 August 2015 ("Black Monday") by 8.48 percent. In January 2016, the market experienced another steep sell-off of 18 percent, and trading was halted on 4 January and 7 January 2016. The market meltdown triggered a global sell-off, with the Dow Jones Industrial Average down 8.2 percent.
} 
may have created an incentive for firms to switch to less pollution-intensive technologies, thereby reducing the demand for carbon allowances. ${ }^{7}$ In the Shenzhen pilot market, the allowance prices are weakly linked to the stock sector indices. However, the Guangdong pilot presents the most interesting results, as carbon prices exhibit statistically significant relationships with compliance events, steel prices, iron ore inventory dynamics, and the JCC and OVX index, whereas the Beijing pilot consistently suggests a lack of pricing fundamentals.

Finally, consistent with Zhao et al. (2016), our findings suggest that the carbon markets sampled in the study are less efficient in an informational sense. When it comes to the explanatory power of the regressions, we document a range of 2 percent to 14 percent in the coefficients of determination across regressions. At first blush, such magnitudes may be reasonable because the regressions also contain contemporaneous values of explanatory variables. However, when autoregressive terms are removed from the system, the adjusted $R^{2} s$ become negligible. Our findings suggest that the relatively high explanatory power does not originate from the inclusion of economic variables but from incorporating autoregressive terms of the returns. This high level of return predictability casts considerable doubt on the informational efficiency of the pilot carbon markets. ${ }^{8}$

Overall, our findings suggest that China's carbon market as a whole is currently in its early stages of development. The weak relationships between carbon allowances and pricing fundamentals are not surprising given the age of the pilot markets (See Montagnoli and De Vries, 2010; Bredin and Muckley, 2011; Creti et al., 2012.). As Chevalier (2009) points out, macroeconomic risk factors also had limited influence in the early periods of the EU-ETS. In the meantime, the lack of strong associations with commonly experienced factors indicates that China's carbon market remains a unique market whose determinants differ from those in other commodity markets.

Our findings present three policy implications for the upcoming national carbon markets in China. First, the four pilots examined in the study exhibit mixed results in terms of their

\footnotetext{
${ }^{7}$ Another energy variable that has been found to be important in the EU-ETS is the fuel-switching behaviour of power companies between coal and gas (Delarue et al., 2010; Keppler and Mansanet-Bataller, 2010). This variable is not tested in the present study because reliable coal and natural gas price data cannot be obtained for China and because electricity generation in China is dominated by coal combustion. The S\&P (2014) reported that more than 70 percent of domestic electricity in 2014 were generated from coal (although this figure is expected to decline). The vast majority of coal power plants are not capable of switching to natural gas, although this situation is also changing fast.

${ }^{8}$ The results on autocorrelation suggest that a simple time-series contrarian trading strategy is likely to be successful in the pilot phase of China's carbon markets. (See Crossland et al., 2013.)
} 
relationships with explanatory variables. However, this result should not be surprising given that inter-market trading of allowances are not permitted across regional pilots. The correlation results and the institutional settings suggest that these regional pilots should be treated as completely separate markets in which pricing fundamentals may vary. Therefore, this finding posts a major challenge for the upcoming integration of these pilots into the national trading scheme. According to the National Development and Reform Commission (NDRC), carbon prices in the national scheme are to be determined by averaging the prices across pilots, which implies that equal weights will be assigned to each pilot. However, the large divergence in prices, coupled with the diverse dynamics across pilots, lead one to question the appropriateness of such a method.

Second, although the overall pricing fundamental appears to be weak in China's pilot markets, our findings suggest that the pilots in Guangdong and Shenzhen may be more mature than those in Beijing and Hubei because of the stronger associations with stock markets and energy price dynamics in the latter pilots. Therefore, policy lessons should be learned from Guangdong and Shenzhen pilots before designing other carbon-trading pilots and the national ETS market.

Third, throughout the sample period, a lack of trading activities highlights the low level of participation by the regulated and the transparency issues in the reporting process, as prices are published separately by each of the regional exchanges. In some cases, the local governing authority appears to be lenient and non-transparent when it comes to compliance, which results in 100 percent compliance in a number of pilot markets. This lack of transparency and market liquidity posts a major threat to the price discovery mechanism. An increased level of reporting transparency and liquidity in the market, especially institutional capital from investment banks and asset managers, may help to improve the efficiency and price-discovery process of these markets.

The remainder of the paper is organised as follows. Section 2 describes the institutional background of all seven pilots, and section 3 details the data employed in the study. Section 4 discusses the methodology, and section 5 reports the empirical results. Section 6 concludes the paper. 


\section{Institutional Settings}

As a cap-and-trade regime, an ETS relies on a cap or a limit on the amount of $\mathrm{CO}_{2}$ companies can emit in a period. Each company is awarded a quota of $\mathrm{CO}_{2}$ emission units, where one unit of allowance equals a certain tonnage of $\mathrm{CO}_{2}$. Companies that emit more than their allocated allowance can either accept the penalty for non-compliance or purchase allowances from companies that have surplus allowances. Over time, the total supply of free quotas/allowances is tightened, which leads to an increase in the allowance price.

Once fully implemented, the China ETS will become the world's largest multi-sector, mandatory greenhouse gas emissions trading regime, doubling the size of the EU-ETS. World Bank estimated a total market value of up to US\$65 billion, covering 3 to 4 billion tonnes of $\mathrm{CO}_{2}$. By 2020, the national carbon market in China would regulate 40 percent of the country's economy. Currently, pilot trading schemes are operating independently in eight regional markets, with the regime varying slightly from one market to another. Table 1 provides a summary of the pilot-trading scheme, including the inception date, total emissions in 2012, emissions covered in 2010, sectors and number of entities covered, the contract ticker, cap emission, compliance date, and monetary penalties for non-compliance for each regional market.

\subsection{Emissions caps and allowance composition}

Unlike the EU-ETS, which has decreasing total emission caps over its three phases (phase I: 2005-2007; phase II: 2008-2012; phase III: 2013-2020), emissions caps and allowance compositions in China vary considerably across pilots because of differences in the jurisdictions' economic structures. As Table 1 shows, in 2013 the local emissions cap ranged from the lowest, 32 million tonnes in Shenzhen, to 408 million tonnes in Guangdong. The Shenzhen pilot covers 635 entities, which is significantly more than most other pilots, but in contrast to the economic structure in Shenzhen, which is largely servicebased, Guangdong relies heavily on energy-intensive industries. Over the same pilot period (2013-2016), caps in all pilots were designed to decease, while that in Tianjin increased from 160 million to 170 million tonnes to allow for increases in industrial production. One of the unique features of China's ETS is how the allowances are designed. Motivated by the nature of an emerging economy, China decomposed the allowances into existing facilities, production expansion, and potential adjustment in order to facilitate economic expansion. 


\subsection{Allowance allocation}

Nearly 100 percent of the allowances in China are allocated free, with the exception of the Hubei (90\%), Beijing (95\%), and Shenzhen (95\%) pilots. The remaining allowances consist of competitive auctions and fixed-price sales. In the Beijing and Tianjin pilots, the allocation is based on historical emissions, historical carbon intensity, and benchmarking. Taking historical carbon intensity into consideration means that allowances that are allocated to electricity and heating providers are determined by their own historical average carbon intensity multiplied by actual supply. This approach gives these providers an incentive to maintain accountability and encourages them to reduce their carbon intensity to avoid additional costs. In the case of the Shanghai pilot, allocation is determined by historical emissions, industrial benchmarks, an early abatement incentive, and a rolling baseline year. The early abatement incentive gives credits to entities that move early to reduce emissions, and the rolling baseline year allows firms to use emission data from the previous year if emissions increased by more than 50 percent from 2009 to 2011. In line with the Shanghai pilot, both the Guangdong pilot and the Hubei pilot have rolling baseline years and industrial benchmarks but do not provide early abatement incentives.

On the other hand, the Chongqing pilot allocates allowances by self-declaration, where the entity requests its own allowance amount. The government is responsible for controlling the allowance caps, which were initially set at the total annual emissions of covered entities in 2008-2012, with the expectation that the total number of allowances shrinks by 4.13 percent per annum through 2016. This intervention by the administration could present a moral hazard that allows a dishonest player to take advantage of honest players. In contrast to other pilots, the Shenzhen pilot combines a multi-round game and industrial benchmarking, where the former is used to allocate free allowances to manufacturers, and latter applies to power and water suppliers. The multi-round game is a design of the collective restriction rule that promotes the honesty of the regulated over the disclosure of emission and production output.

\subsection{Banking, borrowing, and compliance}

Banking of allowances-carrying unused emission allowances forward from the current year for use during the following compliance period-was not restricted during the 20132016 pilot phase, but borrowing was prohibited. Financial penalties applied (except in the Tianjin market) when emitters did not meet their compliance requirements. Credit 
deficiencies could be withdrawn from the company's account or deducted from next year's allocation. Table 1 reports the noncompliance fines, which varied from 50,000RMB to 500,000RMB from one market to another. Other penalties could include "naming and shaming," entry of the noncompliance into the company's credit record, restricted access to special funds for energy conservation, and emission-reduction measures.

From 2014 to 2016, China's ETS experienced three compliance events around June of each year. During 2016, the first compliance period, the Shenzhen pilot achieved a compliance rate of 99.7 percent, with Shanghai at 100 percent, Guangdong at 98.9 percent, and Tianjin at 96.5 percent. The second compliance year, 2015, was the first time that seven pilots achieved full compliance, with Shanghai, Guangdong, Beijing, and Hubei achieving 100 percent compliance, Shenzhen at 99.7 percent, and Tianjin at 99.1 percent. Chongqing did not publish its compliance rate, and penalties against non-compliance have not been announced because Hubei and Chongqing both postponed the compliance deadline to assist the covered entities. In the most recent compliance year, 2016, the Guangdong, Shanghai, and Tianjin pilots once again achieved 100 percent compliance, while Beijing and Shenzhen had only slightly less than perfect compliance, and Hubei and Chongqing failed to publish their compliance data. Eighty-five covered entities in Beijing failed to comply by the deadline. The local DRC again provided a 10-day extension, after which the penalty was three to five times the average allowance price if the pilots were still out of compliance.

\subsection{Offset projects}

China's ETS permits the use of offset credits. Similar to Joint Implementation (JI) and the Clean Development Mechanism (CDM) that are applicable to the EU-ETS, China's carbon markets apply the Chinese Certified Emission Reduction (CCER) as the primary offset mechanism. Emissions-reduction projects like wind, hydro, solar, biomass energy, fuel switch, methane recovery and use, and energy conservation and efficiency are the most popular types of projects. The CCER projects work much like the CDM, where emitters can use credits received when they invest in CCER projects to offset their emissions, thereby reducing the cost of obtaining allowance permits. A lengthy, eleven-stage process is required by the NDRC to register a project. A joint report from ICIS and Hanergy (2014) gives an overview of CCER markets. Table 1 lists the maximum allowable use of CCER as percentages of the caps, which is limited to between 5 percent and 10 percent across seven 
markets. Apart from the limits, each pilot has its own eligibility criteria. For example, Beijing, Hubei, and Guangdong restrict the use of CCERs from other regions in China.

\subsection{The national ETS}

The NDRC has postponed the launch of the national ETS a number of times before and after the original commencement date planned for 2016. Currently, the NDRC, local authorities, and other supporting institutions are finalising the design features of the system (i.e. trading rules, offset credits, and allocation schemes and registry and reporting systems for third-party verifiers). Although the details are yet available to the public, it is expected that emitters in the regulated sectors with annual energy consumption exceeding 10,000 tons of Coal Equivalent in any year from 2013 to 2015 are to be covered. These sectors may include power (generation, cogeneration, and grid), petrochemicals (crude processing, ethylene production), chemicals (ammonia, carbide, and methanol production), building materials (cement clinker production, plate glass production), iron and steel (crude steel production), nonferrous-metals (electrolytic aluminium, copper smelting), paper-making (pulp production, paper-making), and aviation (passenger air transport, air cargo transport, and airports). Implementation and compliance will be enforced by local DRCs.

\section{Data}

\subsection{China's carbon emissions}

The data for China's carbon emissions during the pilot phase, which were obtained from Climate-Connect, include entries for daily prices and trading volume for the individual markets. The dates in the raw datasets were matched to the trading days of the Shanghai Stock Exchange in order to eliminate public holidays.

Table 2, which provides an overview of the raw dataset on all trading pilots, shows that the time series is characterised by a non-negligible number of non-holidays with no trading activity. As a result, we identified three markets as unsuitable for empirical analysis: Chongqing, Shanghai, and Tianjin. Chongqing was excluded because of its low trading activity. As for Shanghai, the trading of carbon emissions in Shanghai includes two relatively long periods with only one day of trading volume between 1 July 2014 and 18 of September 2014 and 14 days with recorded trades from the 2 July 2015 to 26 November 2015 , leaving around six out of the 26 months in the period with no observations. Tianjin is 
excluded because of missing data on trading volume, which means that one cannot determine whether unchanged price levels on consecutive days are due to no trading activity (staleness) in the market or to price levels that emerge from supply and demand market mechanisms. Missing trading volume also impedes the ability to estimate weighted price levels at weekly frequency.

Of the remaining four markets (presented in Table 2), the sample period in Beijing (Hubei) is the longest (shortest). ${ }^{9}$ While in Hubei and Shenzhen trading takes place on a relatively higher portion of the days (98.5\% and 93.2\%, respectively), 33 percent and 35 percent of all trading days in Beijing and Guangdong, respectively exhibit no trading volume, resulting in zero daily returns for these days. Thus, the data series under consideration exhibits a much greater percentage of zero returns than the more commonly analysed financial markets.

The relatively large number of zero returns, combined with the relatively short length of the sample periods, constitutes a major challenge for the empirical analysis. Since the zeros can jeopardize the quality of regressions employed to reveal the impact of macro variables on the carbon market, we analyse the data at a lower frequency. As the time series are limited by data availability, weekly data provide a good compromise between the use of noisy daily data and a too-short span of monthly data. The occurrence of zero returns in the time series is not strongly clustered around certain time periods, and it is likely that the detrimental impact of zero returns is reduced by collapsing the daily data to weekly frequency. To avoid any potential weekday effects, we use Wednesday-to-Wednesday returns. Since the trading volume in all markets varies widely, the last price in a week may originate from a day with only one contract traded, in which case the price is likely to be noisier than the last price observation on a day that had sizable trading. To alleviate this effect, we use weekly average prices weighted by trading volume to calculate weekly returns. ${ }^{10}$

Table 3 reports summary statistics for carbon-emission prices and log returns at weekly frequency when weeks of no trading activity are excluded. Guangdong and Shenzhen are more volatile than Hubei and Beijing, which is consistent with the findings of Rannou and

\footnotetext{
${ }^{9}$ Since multiple vintage years of carbon allowances are traded in the Shenzhen market, the Shenzhen carbon price time series employed in the study is constructed by rolling over vintage years from 2013 to 2016. The availability of allowance vintages is determined by each pilot market's allocation plan. The Shanghai, Beijing, Guangdong, Chongqing, and Hubei markets do not distinguish among vintage years.

${ }^{10} \mathrm{We}$ also used the last price per week (i.e. on Wednesday) for estimate weekly returns. Any missing data on Wednesday was replaced with closing prices from the most recent trading day. The results did not reveal any notable relationships.
} 
Barneto (2016), who show that trading volume Granger causes volatility in the EU-ETS markets. We also observe that returns are skewed and that they have a pronounced excess kurtosis in most cases, which conforms to common characteristics of financial market series. The Kolmogorov-Smirnov test for normality is rejected in all cases for level data and first differences. ${ }^{11}$ The augmented Dickey-Fuller tests for unit roots confirm that level data are nonstationary, whereas log return series are stationary.

Table 3 reports wide differences in prices and returns across the four markets, even though the prices refer to the same quantity and the weekly returns originate from volumeweighted price series, an approach that smooths outliers. For example while carbon emission daily prices in Beijing range between $¥ 32.4$ and $¥ 74.4$, the prices in Shenzhen reach a high of $¥ 83.5$, and Hubei is characterised by a much lower variation of between $¥ 10.7$ and $¥ 27.4$. The large price variations should be expected given how differently these pilots operate. Nevertheless, since the NDRC signalled that carbon prices in the national trading scheme would be the average of all of the pilots, the large variation across regional markets presents a challenge for the upcoming market integration.

Table 4 reports the aggregated trading volume per week for each of the four trading pilots. As a result of the cleaning process, each of these four pilots has at least one tonne of allowance traded per week in the sample period. Although our cleaning approach overcomes the zero-return problem, large variations in trading volume remain, highlighting the importance of volume weighting in constructing the weekly returns time series.

Figure 1 illustrates the autocorrelation structure of the weekly volume-weighted return series with the corresponding $95 \%$ confidence bands. The sample autocorrelation functions are slightly atypical for returns series in the sense that there are notable autocorrelations, especially in the first few lags. These autocorrelations decay slowly and at differing rates across the markets. Overall, other than the larger-than-usual number of zeros, the returns show the usual stylized facts of asset returns, including volatility clustering and fat tails. We took the autocorrelation in the log returns into account when we configured the lags for the dependent variable in the regressions. This approach will also allow us to assess the predictive component for the mean.

\footnotetext{
${ }^{11}$ Similar conclusions regarding the normality of the series considered are made with Shapiro-Wilk, Cramervon Mises, and Anderson-Darling tests for normality.
} 


\subsection{Explanatory variables}

This study provides an extensive overview of the impact of various macro variables, such as stock markets, energies and metals, and market sentiment, on the emerging carbon emission market in China. Daily (and weekly) values of the variables are obtained from Bloomberg and Datastream. All data are quoted in Chinese RMB. Any missing values that are due to data unavailability or asynchronicity of trading days between China's markets and the international markets are populated with the most recent available daily value. Table 5 provides a summary of these variables with the corresponding Bloomberg/Datastream tickers.

China's stock market is proxied by the Shanghai Stock Exchange Composite Index (SSE) and the Shenzhen Stock Exchange Composite Index (SZSE). SSE is a capitalisation weighted index which tracks the performance of all A-shares and B-shares listed on the SSE. SZSE, an actual market-cap weighted index with no free-float factor, reflects the performance of all A and B shares listed at the SSE. The analysis uses weekly log returns of both of these two indices, as Shanghai has traditionally hosted the biggest state-owned companies, such as banks and energy firms, while the Shenzhen market is composed of companies from the private sector. In addition, to capture the impact of the sectors of the economy that are likely to be relevant to the carbon market, the analysis includes the SSE Energy, Materials, Industrials and Utilities sector indices. The bond market is represented by the China Government 10-year generic bid yield. The yields are based on the bid side of the markets and are updated on an intraday basis. ${ }^{12}$

The data used for the energy and metals markets are the spot price series of coal, steel, iron ore inventory level, natural gas, and crude oil. China's coal data is the thermal coal Qinhuangdao $5500 \mathrm{kcal} / \mathrm{kg}$ spot price, and we use Australian Newcastle Port thermal coal $6000 \mathrm{kcal} / \mathrm{kg}$ in order to incorporate international dynamics. The steel price refers to the hot rolled steel $3 \mathrm{~mm}$ export price in Shanghai. Iron ore inventory data aggregate the total inventory of iron ore at all of China's ports. The natural gas data are the liquid natural gas price in Asia and the NYMEX natural gas prices. For crude oil prices, we use Daqing crude oil for domestic pricing information, crude oil cocktail Japan customs-cleared crude cost

\footnotetext{
${ }^{12}$ To ensure robustness and comparability to other studies on carbon markets (e.g. Aatola et al., 2013), we also run the analysis with the market portfolio excess returns calculated as the returns of SZSE and SSE in excess of the government bond rate. The excess return series is highly correlated with the underlying stock indices and does not allow for conclusions other than those presented in the paper. The results are not reported for the sake of parsimony.
} 
(JCC) for regional market dynamics, and Brent crude oil for international shocks. Variables used in other studies (e.g. Aatola et al, 2013; Chevallier, 2009) such as electricity prices could not be taken into account due to the unavailability at daily or weekly frequencies. ${ }^{13}$

Finally, we explore the relationship between carbon prices and broad market sentiment in China using three proxies: China VIX, OVX, and a China market sentiment indicator. China VIX denotes the AlphaShares Chinese volatility index, which measures the implied volatility of options on the FTSE Xinhua China 25 and Hang Seng indices. OVX refers to the CBOE crude oil volatility index, which measures the market expectation of 30-day volatility of crude oil prices. China sentiment measures the inflow/outflow of CSOP Chinarelated ETFs that have an AUM of larger than CNY 200 million.

Figure 2 shows how the variables developed over time, and Table 5 contains summary statistics for all variables from 2 April 2014 through 31 December 2016. The Daqing crude oil is the most volatile variable among the energies, and the coal price has the least variation because of the data's staleness. VIX and OVX are the most volatile series because of the nature of these variables. Since the levels of all variables (including bond yield) are nonstationary, $\log$ differences are consistently stationary and are used throughout the analysis. ${ }^{14}$

\section{Methodology}

The methodology employed follows an Arbitrage Pricing Theory approach according to which the return from a financial asset can be modeled as a linear function of various macroeconomic factors. In line with the literature that addresses this research question for the EU-ETS (e.g. Chevallier, 2009; Aatola et al., 2013), the analysis is based on regressions of the following form:

$$
\Delta y_{t}=\alpha+\gamma(L) \Delta y_{t}+\beta^{\prime} \Delta X_{t}+\varepsilon_{t},
$$

where $\Delta y_{t}$ is the log-differenced carbon price, $L$ is the lag operator, and $X$ is the vector of explanatory variables. ${ }^{15}$ Extant research that addresses the relationship between carbon

\footnotetext{
${ }^{13}$ Unlike in the western world, China's electricity generation and power grid companies are largely stateowned, although China is currently exploring a more market-based electricity industry.

${ }^{14}$ The results of the stationarity test are not shown but are available on request.

${ }^{15}$ The variables selected are macro-level financial risks (stock market and bond yield), energies and metals price dynamics (coal, steel, iron ore, LNG, gas and oil), and the overall sentiment of China's market (CHVIX and OVX). See the data section for details.
} 
markets and macroeconomic factors applies GARCH-type extensions to account for the stylized facts that are observable in series of log differences of carbon prices (e.g. Aatola $e t$ $a l ., 2013)$. The majority of studies on the carbon market use daily data of the EU-ETS that spans longer sample periods that do not feature a comparable number of zero daily returns. Investigating the time series properties of carbon prices, Paolella and Taschini (2008) employ a data set of emission allowances from 1999 to 2006 that are characterised by 29 percent zero returns. Given that the abundance of zeros precludes effective use of standard GARCH models, Paolella and Taschini (2008) apply a GARCH-type model with mixednormal innovations to the data and confirm its suitability in these settings. However, the time series they consider contains 1,780 observations, so it exceeds by far the length of the Chinese data set in the study at hand, which is limited by the beginning of the pilot phases in late 2013 or early 2014. Since maximum likelihood estimates of GARCH-type models are significantly negatively biased in small samples and since at least 500 observations are needed to fit a GARCH $(1,1)$ model (which is one of the most parsimonious model forms) to financial return series (Hwang and Pereira, 2006), the small sample size prohibits the use of more elaborate models. We handle possible heteroscedasticity and autocorrelation in the error terms by running all estimations with Newey-West HAC standard errors. ${ }^{16}$

Table 6 reports the cross-correlations among the log differences of the chosen variables. Panel A reports the correlations among the various pilots' carbon prices, Panel B presents the results on stock indices, and Panels $\mathrm{C}$ and $\mathrm{D}$ show the energies and sentiment variables, respectively. The results in Panel A show that price dynamics appear to be independent from one market to another, as low and negative correlations are generally the case across pilots. This result should be expected because these markets are separate from each other and allowances are not tradable or transferable across markets. These factors also suggest that the fundamentals that drive prices in the four regional pilots may differ.

Panel B shows strong correlations among China's sector indices and with the broad equity market indices. In addition, the Shenzhen pilot is the only pilot market that exhibits positive

\footnotetext{
${ }^{16} \mathrm{GARCH}$ and EGARCH specifications were fitted to the return series (with and without zeros) in the course of analysis. GARCH extensions result in $\mathrm{ARCH}$ and $\mathrm{GARCH}$ parameters that are insignificant for the most part but that consistently sum to more than 1 (and, thus, rule out an IGARCH model as an alternative), which is a not desirable result. Fitting EGARCH models, which have the appealing feature of not imposing parameter restrictions, resulted in estimates that sometimes did not converge. When convergence did occur, the parameter estimates varied widely with minor changes in the initial values. Overall, these results suggest that GARCH models are not suitable for time series of such restricted length, aggravated by the presence of zero returns.
} 
correlations with the broad stock market and sector indices. In Panel C, which shows the result when energy variables are introduced to the matrix, Brent crude oil exhibits positive and significant correlations with sector indices and steel prices in China, confirming the role of crude oil as a fundamental input for the economy. ${ }^{17}$ The JCC is positively correlated with NYMEX natural gas prices. In addition, the results in Panels B and C suggest that the dynamics of energy prices are not significantly correlated with carbon prices in China.

Finally, Panel D indicates that changes in broad market sentiment are not transmitted to carbon markets, as the correlations among sentiment measures and stock markets are generally negative in the sample period examined. As expected, higher market volatility generally leads to lower stock returns. Panel D also shows that market sentiment is negatively correlated with the international crude oil prices. Overall, the correlations in Table 5 suggest potential collinearity problems between the explanatory variables, so we conduct univariate analysis and principal component analysis (PCA) to mitigate these concerns.

\section{Empirical Results}

\subsection{Market dynamics in each pilot}

Before presenting the regression results, we first take a deep dive into the developments of allowance prices and trading volume in each pilot market. Figure 3 illustrates the daily prices, returns, and volumes for allowances traded in Beijing, Guangdong, Hubei, and Shenzhen. In general, prices in the pilot phase range from 20 to 120RMB across markets. The trading volumes monotonically spike around July in each year, which coincides with the compliance events and indicates that China's carbon markets are less active outside of the compliance events. This market behaviour appears to be consistent with the EU-ETS. Hitzemann et al. (2015) report that trading is relatively calm on the days before compliance events, but trading volumes are significantly higher on compliance days as the market incorporates the emission permit option prices.

In the Beijing pilot, 12.67 million tons of carbon allowance were traded in the sample period. The lowest overall trading volume occurred during the first compliance period in

\footnotetext{
${ }^{17}$ Daqing crude oil prices report slightly higher correlations with stock indices.
} 
2014. In 2015, the Beijing pilot covered 10 percent more firms than it did in 2014 and allowed individual investors to participate in the market. These changes boosted liquidity, as the volumes traded averaged higher during the second compliance period. However, trading activities declined considerably later in 2015, as the demand from the individual investors who were attracted by the high trading prices was insufficient to propel the entire market. As for the most recent compliance period, in 2016, trading activities again peaked in mid-June, ahead of the other pilots, and the large majority of volume occurred in the days leading up to the deadline.

Moving on to the Guangdong pilot market, where a total trading volume of 30.73 million tons of carbon allowance was recorded, trading was significantly more active in 2015 , the second compliance period (roughly five times the amount traded in the same period in 2014). The increase in volume was mainly due to a switch from the 'grandfathering' allocation system to a more auction-based system. Later in the year, the Guangdong DRC announced that the allowance amount emitters declared must exceed the total amount issued by the local DRC, indicating that the auction price would be linked to the price on the secondary market. Prior to the 2016 compliance event, an auction held on June 8 failed to generate any transactions. According to the pilot rules, the auction was invalid because the amounts auctioned were more than the amount that entities bid upon. After July 2016, the auction portion of each covered industry is allowed to vary from 3 percent to 5 percent. These unique policy dynamics are part of the reason that prices in Guangdong appear to be more volatile than those in the other markets.

The Hubei pilot traded a total of 36.73 million tons of carbon allowance in the sample period. Compared with the other markets, the Hubei pilot remained relatively liquid even after the compliance period in 2015 , with an average daily volume of 85,694 tons. This difference is due to a regulation that surplus allowances would be cancelled if they were not from the secondary market. However, trading was spurred in September 2015 by a rule that required emitters to surrender unused surplus allowances after each compliance deadline. In the third quarter of 2015, the Hubei pilot expanded the rules by requiring cement, heat, and combined heat firms (in addition to power and industries) to benchmark performance. In early 2016, trading activities were slow as the market anticipated the launch of HBEA futures. Prices fell sharply during the compliance period, and the local DRC implemented a trading curb to calm the market. Because of the short time between the compliance announcement (July 8) and the deadline (July 25), the supply of allowances in the market 
was stretched before prices recovered. Hubei also tightened the CCER rule such that only biogas and forest sink projects were eligible for compliance.

In the Shenzhen market, 17.92 million tons of allowance were traded. The Shenzhen pilot is the only market to have allocated all three years of emissions allowances at once and to have allowed participants to reserve surplus allowances for future compliance and trading. This approach helped the market to remain relatively liquid and explains the less abrupt volume spikes during the 2014 and 2015 compliance events, as emitters generally had sufficient allowance to meet compliance. Not surprisingly, the prices and volume increased considerably during the most recent compliance, as the emitters were unclear about whether unused allowances could be carried forward to the upcoming national ETS. In September 2016, Shenzhen announced the list of covered entities, the allowance allocation method, and the compliance arrangement for 2017, resulting in a boost in trading for SZA16 allowances.

\subsection{Macro-level financial risks}

We now turn our attention to macro-level financial risks and their potential links with the carbon allowance prices in each pilot. Oberndorfer (2009) and Veith et al. (2009) demonstrate that the most affected companies' (i.e. electricity) stock returns under the EUETS are positively correlated with carbon prices and conclude that firms can not only pass the regulatory burden to customers but also gain profits by overcompensating for the costs. Motivated by their findings, we investigate these dynamics in China's trading pilots. Table 7 reports the univariate regression results on all explanatory variables with intercepts omitted. The results on stock indices can be found in Panel A, which shows no statistically significant relationships between carbon prices and stock prices in Beijing or Guangdong, although carbon prices in Hubei load weakly on the utilities index. Since the utilities index consists mostly of energy companies (e.g. 600021: Shanghai Electric Power; 600008: Beijing Capital), the observed link suggests that these high emitters may have factored carbon prices into their operations.

The Shenzhen pilot prices have a positive relationship with the energy and materials sector indices and both overall market indices. This result is somewhat consistent with the results in Hubei, as materials companies are among the highest emitters in the greater Shenzhen region. The pronounced positive impact of the energy and materials sector index on the carbon market in Shenzhen suggests that a 1 percent increase in the sector index is 
associated with an increase of around 0.26 percent in the carbon prices. However, the low $R^{2} \mathrm{~S}$ across the board suggest that stock market information in general is inadequate to explaining the variations of carbon prices in China.

\subsection{Innovations in energies and metals prices}

In this section, we examine whether energies and metal prices contain information that is useful in explaining the variations in carbon allowance prices. Aatola et al. (2013) document a negative influence of coal prices on the price of carbon, whereas Lutz et al. (2013) find a negative relationship only in certain periods. Earlier studies, such as Mansannet-Bataller et al. (2007) and Alberola et al. (2008), provide evidence that carbon prices in the EU-ETS are linked to oil, gas, and coal prices. Motivated by these findings, we investigate the relationship between carbon allowance prices and variations in coal, steel, iron ore inventory, gas, and crude oil prices. To separate domestic shocks from regional and global shocks, we employ price series that reflect China, Asia and global demand and supply dynamics.

Our rationale for variable selection begins with China's being the world's largest producer of steel. Most of China's steel industry developed through a system of state-owned enterprises, where an entire city or community specialised in the production of steel (Price et al., 2002). Iron and steel production is more energy-intensive in China than it is in other developing countries, such as Brazil and Poland (Worrell et al., 1997), so data on the prices of iron ore inventory and steel contain dynamics that are influenced by a variety of economic functions. In addition, China's energy imports, fuelled by rapid economic expansion, have grown markedly over the past decade. Therefore, we consider coal, crude, and gas prices not only in China (coal, steel, and iron ore inventory) but also in Asia (JCC, Asia LNG, and Australia coal), as well as global benchmarks (Brent and NYMEX gas). The Japan Crude Cocktail (JCC) is selected because of its benchmarking role in the LNG price in Asia (Aguilera et al., 2014). The JCC measures the average monthly price of crude oil imported into Japan. ${ }^{18}$ In addition, since Japan, South Korea, China, and Taiwan are all major importers of thermal coal from Australia, we employ the Australian Newcastle FOB $6300 \mathrm{kcal} / \mathrm{kg}$ thermal coal prices (Alim et al., 2017).

\footnotetext{
${ }^{18}$ Historically, natural gas pricing in Asia has been pledged to crude oil, and it is only recently that alternatives have been introduced. Some current contracts are reputed to contain references to Henry Hub to account for a portion of the weight in the pricing mechanisms. For many years, the pricing was tied to the Japanese Crude Cocktail (JCC).
} 
Table 7's Panel B presents the regression results on energy and metal prices based on the $\log$ differences of volume-weighted weekly average prices. Consistent with the results in Panel A, energies and metal prices dynamics contain no information that is relevant to allowance price variations in the Beijing and Guangdong pilots. In the Shenzhen pilot, it appears that changes in the iron ore inventory correlate positively with carbon prices. In addition, in both Hubei and Shenzhen pilot, Brent crude oil has a statistically significant relationship with the allowance prices. While the positive significance of crude oil in Hubei conforms to the existing literature (Chevallier, 2009; Chevallier, 2011; Aatola et al., 2013; Lutz et al., 2013), the negative sign in Shenzhen is at odds with previous results and suggests that high (low) fuel prices contribute to the decrease (increase) in carbon prices. Once again, the low $R^{2}$ s suggest that variations in energy and metal prices are inadequate to explaining the dynamics of China's carbon prices. Findings in Panel B present several implications, among them the lack of statistically significant relationships with established energy variables that reflect domestic, regional, and global market dynamics and suggest that the pricing fundamentals of China's carbon market remain relatively weak, as variables that have been found to be informative in the EU-ETS are not currently priced in China's trading pilots. The differences in Brent crude price loadings may also suggest that the carbon price dynamics in the Hubei and Shenzhen pilots differ widely.

\subsection{Market sentiments}

The lack of a strong association between carbon prices and economic fundamentals prompts us to investigate factors that incorporate investor behaviours and how these factors might affect carbon prices. Therefore, we seek to determine whether changes in overall market sentiment can influence the carbon prices in the four pilots. The Chinese VIX (CHVIX) index, which is regarded as the "investor fear gauge" (Baker and Wurgler, 2007), measures the implied volatility of options on China's equity indices, and the most liquid derivatives markets using a methodology similar to the calculation of VIX. Provided by AlphaShares, CHVIX computes the 30-day weighted-average implied volatility of the four options that are closest to the at-the-money strike of the two benchmark indices. Higher volatility readings are associated with high volatility, which reflects investor fear and uncertainty. In contrast, low volatility typically corresponds to less stressful or even complacent times in the marketplace. In the equities literature, measures of stock market volatility are employed to explain risk premia (Kempf et al., 2012) or as explanatory variables in forecasting models (Minton et al., 2002). We use the CHVIX to examine how 
carbon prices in each pilot respond to expectations on the state of the economy as reflected by the market trend. Our sample period also covers the recent (2015-16) meltdown in China's equity market, which was characterised by vast swings in market sentiment.

For robustness reasons, we consider a second measure of sentiment, proxied by the inflow/outflow of CSOP Asset Management's China-related ETFs that have an AUM of larger than CNY200m. As the correlation matrix suggests, the CHVIX is not highly correlated with the CSOP sentiment measure, so the CHVIX provides a different perspective for our analysis. Furthermore, given the statistical significance of international crude oil prices in Hubei and Shenzhen, we include the CBOE crude oil ETF volatility index $(\mathrm{OVX})$ as an additional sentiment variable. The OVX measures the market's expectation of 30-day volatility of crude oil prices by applying the VIX methodology to the US oil fund options, spanning a wide range of strike prices. Previous studies find a spillover effect between oil shock and stock market trends (Kang et al., 2015; Maghyereh et al., 2016; Andrada-Félixa, et al., 2017). These results can be found in Panel C of Table 7. The regression results monotonically suggest that, regardless of differences in definitions, carbon prices in all four pilots do not respond to changes in market sentiment, suggesting that equity market volatility had minimal impact on the dynamics of China's carbon markets in the sample period.

\subsection{Multivariate results}

Multiple regression analyses for all four pilots were executed, but to mitigate potential criticisms about data-snooping, we reduced the number of regressions for each pilot from nineteen to two with local and international shocks. In addition, as the correlation analysis indicated, the degree of correlation varies among stock market, oil, and sentiment variables, so a multifactor framework aids in incorporating these interactions and sheds light on the joint determination of allowance prices. We consider two systems of regressions, one that focuses on China and regional dynamics and one that incorporates global energy price dynamics. For each regression, the following variables are introduced in addition to the energy, metals, and market sentiment variables.

First, to reduce potential distortions induced by collinearity concerns, principal component analysis (PCA) was performed to extract the first three common factors among the stock indices. Second, the autocorrelation structures inherent in the carbon price time series were 
taken into account by including autoregressive terms. ${ }^{19}$ Third, to investigate the potential impact of compliance events, a dummy variable that corresponds to a specific compliance period in each pilot was introduced to capture these dynamics. Fourth, we include a lagged volatility variable that captures the one-week lagged volatility of each carbon pilot market. Since it is possible to have some collinearity inherent in the residual series, we investigated the variance inflation factors obtained with these explanatory variables and found no serious multicollinearities, so spurious regression results can be ruled out.

Table 8 presents the multiple regression results. Panel A reports the China-based results, and Panel B reports China's dynamics and international dynamics. The results in Panel A reveal that carbon prices across pilot markets load negatively on autoregressive terms, suggesting that returns in the recent past negatively predict future returns. In addition, the PCA loadings suggest that, with the exception of the Shenzhen and Guangdong carbon markets, stock market indices do not yield statistically significant results after controlling for energies, sentiment variables, and autoregressive terms. However, these loadings $(0.01 \%)$ are marginal compared to the univariate results. Finally, since the trading volume in individual markets surges around compliance periods, it is natural to question whether the results are influenced by these periods. A dummy variable for the months of compliance and/or the months of pronounced higher levels of trading activity is consistently insignificant across all four markets except the Guangdong pilot. This result also suggests that the impact of macro variables on the carbon markets is not sensitive to periods of disproportionally higher trading volumes (i.e. around compliance events). The results shown in Table 8's Panel A also indicate that volatility is negatively related to carbon prices in the Beijing pilot. The negative loadings on volatility suggest that a 1 percent decrease in lagged volatility is followed by a 0.78 percent increase in the carbon prices in Beijing. Finally, in terms of the energies and metals price variables, carbon prices in the Guangdong pilot appear to load positively on the JCC but negatively on changes in the iron ore inventory. However, no statistically significant relationships are present in other pilot markets, ${ }^{20}$ again suggesting the presence of interactions among variables in the system that cannot be captured by study single variables. After controlling for all China-based variables,

\footnotetext{
${ }^{19}$ To account for any autocorrelations at weekly frequency, autoregressive terms at the first, second, and third lags are included in the regressions. The lag structure is chosen after analysing information criteria and repeating the analysis with additional lag lengths to ensure robustness. Any higher-order lags are insignificant (Figure 2).

${ }^{20}$ The findings are consistent when Daqing crude oil prices are employed in place of the JCC.
} 
the findings suggest that the Guangdong pilot's prices are positively correlated with the average price of customs-cleared crude oil imports into Japan.

Table 8's Panel B reports the findings when international energy price dynamics are introduced to the system. The findings for the Beijing and Shenzhen pilots remain unchanged, but the significance of Hubei's and Shenzhen's carbon prices on Brent crude oil disappears after controlling for other dynamics in the system. However, in the Hubei pilot, international natural gas has a significant positive relationship with carbon prices, suggesting that an increase in energy prices would lead to an increase in carbon prices in Hubei. In line with Mansannet-Bataller et al. (2007) and Alberola et al. (2008), an increase in energy prices signals an increase in energy demand, and an increase in energy demand suggests an increase in the generation of carbon emissions, which should increase the demand for allowances. In the Guangdong pilot market, the loadings and significance on explanatory variables also remain largely unchanged after including international crude oil and gas dynamics. The additional observation is the negative loading on OVX, which suggests that carbon allowance prices in Guangdong increase when the volatility of international crude oil declines.

Table 8 presents a range of 2 percent to 14 percent in the coefficients of determination across regressions. These magnitudes may appear to be reasonable at first because the regressions are not predictive, as they contain also contemporaneous values of explanatory variables. However, when autoregressive terms are removed from the system, the adjusted

$R^{2}$ s become negligible. Overall, these findings suggest that the relatively high explanatory power does not originate from the inclusion of economic variables but from incorporating autoregressive terms of the returns. This high level of return predictability casts considerable doubt on the informational efficiency of the pilot carbon markets in China, that these pilot markets are immature, and that the price fundamentals are weak in the sample period.

\section{Conclusion}

This paper examines the empirical relationship between carbon prices and macro factors in China's pilot trading scheme. For markets in Beijing, Guangdong, Hubei, and Shenzhen in the 2014-2016 period, we investigate the empirical links between allowance prices and stock markets, energy and metal prices, and market sentiment in China's regional and 
global markets. Our results suggest that carbon prices in Hubei are weakly linked to international natural gas prices, but not the international crude, but none of the other markets have a significant relationship. Our results also indicate that energy, utilities, industrial, and materials sector indices are positively related, to varying degrees, to the allowance prices in Hubei and Shenzhen, suggesting that high emitters in the region may have factored the carbon prices into their production mix. Finally, since a relatively stronger association with economic variables was found in the Guangdong pilot, our results suggest that lessons could be learned for the upcoming national ETS market.

The findings presented in this study suggest that China's carbon market is currently in its early stages of development. The relationship between price and market fundamentals is weak, and the market is not informationally efficient. These findings are not surprising given the age of the market; nevertheless, the implementation of the pilot serves as an important foundation for the development of an integrated national market beginning in 2017. This paper presents an open invitation to the literature to study China's cap-and-trade system. As more data and trading activities become available, employing econometrically advanced models will enable further examination of the returns and the volatility of carbon prices and volume.

\section{References}

Aatola, P., Ollikainen, M., \& Toppinen. A. (2013) Price determination in the EU ETS market: Theory and econometric analysis with market fundamentals. Energy Economics, 36, 380395.

Aguilera, R. F., Inchauspe, J., \& Ripple, R. D. (2014). The Asia Pacific natural gas market: Large enough for all? Energy Policy, 65, 1-6.

Aldy, J. E., \& Stavins, R. N. (2012). The promise and problems of pricing carbon: theory and experience. The Journal of Environment \& Development, 21(2), 152-180.

Alim., A, Hartly, P. \& Lan, Y. (2017). Asian Spot Prices for LNG and other Energy Commodities, The Energy Journal (forthcoming).

Andrada Félix, J., Fernandez-Perez, A., \& Sosvilla Rivero, S. (2017). Fear connectedness among asset classes. Working paper at Research Institute of Applied Economics, Universitat de Barcelona. 
Baker, M., \& Wurgler, J. (2007). Investor sentiment in the stock market. The Journal of Economic Perspectives, 21(2), 129-151.

Benz, E., \& Trück, S. (2009). Modeling the price dynamics of CO 2 emission allowances. Energy Economics, 31, 4-15.

Bloomberg (2016). China urged to avoid excess carbon quotas in national trading. Retrieved on May 2, 2016 from http://www.bloomberg.com/news/articles/2016-03-02/china-urged-toavoid-excess-carbon-quotas-in-national-trading

Bredin, D., \& Muckley, C. (2011). An emerging equilibrium in the EU emissions trading scheme. Energy Economics, 33, 353-362.

Chevallier, J. (2009). Carbon futures and macroeconomic risk factors: A view from the EU ETS. Energy Economics, 31, 614-625.

Chevallier, J. (2011). Detecting instability in the volatility of carbon prices. Energy Economics, 33, 99-110.

Cong, R. G., \& Wei, Y. M. (2010). Potential impact of (CET) carbon emissions trading on China's power sector: A perspective from different allowance allocation options. Energy, 35, 3921-3931.

Creti, A., Jouvet, P. A., \& Mignon, V. (2012). Carbon price drivers: Phase I versus Phase II equilibrium? Energy Economics, 34, 327-334

Crossland, J., Li, B., \& Roca, E. (2013). Is the European Union Emissions Trading Scheme (EU ETS) informationally efficient? Evidence from momentum-based trading strategies. Applied Energy, 109, 10-23.

Declercq, B., Delarue, E., \& D'haeseleer, W. (2011). Impact of the economic recession on the European power sector's CO2 emissions. Energy Policy, 39, 1677-1686.

Delarue, E. D., Ellerman, A. D., \& D'haeseleer, W. D. (2010). Robust MACCs? The topography of abatement by fuel switching in the European power sector. Energy, 35, 1465-1475.

Hintermann, B., Peterson, S., \& Rickels, W. (2016). Price and market behavior in Phase II of the EU ETS: Areviewof the literature. Review of Environmental Economics and Policy, 10, $108-128$.

Hitzemann, S., Uhrig-Homburg, M., \& Ehrhart, K. M. (2015). Emission permits and the announcement of realized emissions: Price impact, trading volume, and volatilities. Energy Economics, 51, 560-569.

Hwang, S., Pereira, P.L.V. (2006). Small sample properties of GARCH estimates and persistence. The European Journal of Finance, 12, 473-494.

ICIS and Hanergy. (2014). The essentials of Chinese Certified Emission Reduction (CCER). Retrieved on February 2, 2016 from http://www.icis.com/press-releases/china-tschachccer-whitepaper/ 
Jiang, J., Xie, D., Ye, B., Shen, B. \& Chen, Z. (2016). Research on China's cap-andtrade carbon emission trading scheme: Overview and outlook. Applied Energy, 178, 902917.

Kang, W., Ratti, R. A., \& Yoon, K. H. (2015). The impact of oil price shocks on the stock market return and volatility relationship. Journal of International Financial Markets, Institutions and Money, 34, 41-54.

Kempf, A., Korn, O., \& Uhrig-Homburg, M. (2012). The term structure of illiquidity premia. Journal of Banking \& Finance, 36, 1381-1391.

Keppler, J. H., \& Mansanet-Bataller, M. (2010). Causalities between CO 2, electricity, and other energy variables during phase I and phase II of the EU ETS. Energy Policy, 38, 33293341.

Li, W. Liu, C., Ding, Y. \& Zhang, Y.-W. (2017). The impacts of policy mix for resolving overcapacity in heavy chemical industry and operating national carbon emission trading market in China. Applied Energy, 204, 509-524.

Liu, L., Chen, C., Zhao, Y., \& Zhao, E. (2015). China' s carbon-emissions trading: Overview, challenges and future. Renewable and Sustainable Energy Reviews, 49, 254-266.

Löfgren, Å., Wråke, M., Hagberg, T., \& Roth, S. (2014). Why the EU ETS needs reforming: an empirical analysis of the impact on company investments. Climate policy, 14, 537-558.

Lutz, B. J., Pigorsch, U., \& Rotfuß, W. (2013). Nonlinearity in cap-and-trade systems: The EUA price and its fundamentals. Energy Economics, 40, 222-232.

Maghyereh, A. I., Awartani, B., \& Bouri, E. (2016). The directional volatility connectedness between crude oil and equity markets: New evidence from implied volatility indexes. Energy Economics, 57, 78-93.

Minton, B. A., Schrand, C. M., \& Walther, B. R. (2002). The role of volatility in forecasting. Review of Accounting Studies, 7, 195-215.

Montagnoli, A., \& De Vries, F. P. (2010). Carbon trading thickness and market efficiency. Energy Economics, 32, 1331-1336.

Oberndorfer, U. (2009). EU emission allowances and the stock market: evidence from the electricity industry. Ecological Economics, 68, 1116-1126.

Paolella, M.S., Taschini, L. (2008) An econometric analysis of emission allowance prices. Journal of Banking \& Finance, 32, 2022-2032.

Prete, C. L., \& Norman, C. S. (2013). Rockets and feathers in power futures markets? Evidence from the second phase of the EU ETS. Energy Economics, 36, 312-321.

Price, L., Sinton, J., Worrell, E., Phylipsen, D., Xiulian, H., \& Ji, L. (2002). Energy use and carbon dioxide emissions from steel production in China. Energy, 27(5), 429-446. 
Rannou, Y., \& Barneto, P. (2016). Futures trading with information asymmetry and OTC predominance: Another look at the volume/volatility relations in the European carbon markets. Energy Economics, 53, 159-174.

Ren, C. \& Lo, A. Y. (2017). Emission trading and carbon market performance in Shenzhen, China. Applied Energy, 193, 414-425.

Reuters (2014). China's national carbon market to start in 2016 - official. Retrieved on May 3, 2016 from http://uk.reuters.com/article/china-carbontrading-idUKL3NOR107420140831

S\&P. (2014). Rise in China's coal-fired capacity in 2014, 2015 may not boost thermal coal prices: UBS. Retrieved on May 2, 2016 from http://www.platts.com/latestnews/coal/singapore/rise-in-chinas-coal-fired-capacity-in-2014-2015-21573872

Sanin, M. E., Violante, F., \& Mansanet-Bataller, M. (2015). Understanding volatility dynamics in the EU-ETS market. Energy Policy, 82, 321-331.

Tang, W., \& Wu, L. (2013). Efficiency or equity? Simulating the carbon emission permits trading schemes in China based on an inter-regional CGE model. In 16th Annual Conference on Global Economic Analysis.

The Telegraph. (2015). Emissions impossible as EU fails to police main anti-pollution scheme. Retrieved on 20 May, 2017 from http://www.telegraph.co.uk/news/earth/energy/12022964/Emission-impossible-as-EUfails-to-police-main-anti-pollution-scheme.html

Veith, S., Werner, J. R., \& Zimmermann, J. (2009). Capital market response to emission rights returns: Evidence from the European power sector. Energy Economics, 31, 605-613.

Worrell, E., Price, L., Martin, N., Farla, J., \& Schaeffer, R. (1997). Energy intensity in the iron and steel industry: a comparison of physical and economic indicators. Energy policy, 25, 727 744.

Wu, R., Dai, H., Geng, Y., Xie, Y., Masui, T. \& Tian, X. (2016). Achieving China’s INDC through carbon cap-and-trade: Insights from Shanghai. Applied Energy, 184, 1114-1122.

Xiong, L., Shen, B., Qi, S., Price, L., \& Ye, B. (2017). The allowance mechanism of China's carbon trading pilots: A comparative analysis with schemes in EU and California. Applied Energy, 185, 1849-1859.

Ye, B., Jiang, J., Li, C., Miao, L. \& Tang, J. (2017). Quantification and driving force analysis of provincial-level carbon emissions in China. Applied Energy, 198, 223-238.

Yuan Y., Min-Jun, S., Na, L., \& Sheng-Lü, Z. (2012). Intensity allocation criteria of carbon emissions permits and regional economic development in China-Based on a 30province/autonomous region computable general equilibrium model. Advances in Climate Change Research, 3, 154-162.

Zhang, Z. (2015). Carbon emissions trading in China: the evolution from pilots to a nationwide scheme. Climate Policy, 15, S104-S126. 
Zhang, C., Wang, Q., Shi, D., Li, P. \& Cai, W. (2016). Scenario-based potential effects of carbon trading in China: An integrated approach. Applied Energy, 182, 177-190.

Zhao, X. G., Jiang, G. W., Nie, D., \& Chen, H. (2016). How to improve the market efficiency of carbon trading: A perspective of China. Renewable and Sustainable Energy Reviews, 59, 1229-1245. 
Table 1 Pilot phase basic summary

\begin{tabular}{|c|c|c|c|c|c|c|c|}
\hline Exchange & $\begin{array}{l}\text { Shenzhen Climate } \\
\text { Exchange }\end{array}$ & $\begin{array}{l}\text { Shanghai Environment and } \\
\text { Energy Exchange }\end{array}$ & $\begin{array}{l}\text { China Beijing } \\
\text { Environment Exchange }\end{array}$ & $\begin{array}{l}\text { China Emissions } \\
\text { Exchange } \\
\text { (Guangdong) }\end{array}$ & $\begin{array}{l}\text { Tianjin Climate } \\
\text { Exchange }\end{array}$ & $\begin{array}{l}\text { China Hubei Emissions } \\
\text { Exchange }\end{array}$ & $\begin{array}{l}\text { Chongqing Carbon } \\
\text { Emissions Trading } \\
\text { Centre }\end{array}$ \\
\hline Inception & $18 / 06 / 2013$ & $26 / 11 / 2013$ & $28 / 11 / 2013$ & $19 / 12 / 2013$ & $26 / 12 / 2013$ & $2 / 04 / 2014$ & $16 / 06 / 2014$ \\
\hline $\begin{array}{l}\text { Total Emissions } \\
\text { (2012) }\end{array}$ & $153 \mathrm{Mt}$ & $297 \mathrm{Mt}$ & $188 \mathrm{Mt}$ & $610 \mathrm{Mt}$ & $215 \mathrm{Mt}$ & $463 \mathrm{Mt}$ & $243 \mathrm{Mt}$ \\
\hline $\begin{array}{l}\text { Coverage in } \\
2010\end{array}$ & $38 \%$ & $\sim 55 \%$ & $\sim 40 \%$ & $\sim 60 \%$ & $\sim 60 \%$ & $\sim 35 \%$ & $\sim 60 \%$ \\
\hline Sectors Covered & $\begin{array}{l}\text { Power, water } \\
\text { supply, } \\
\text { manufacturing, } \\
\text { building }\end{array}$ & $\begin{array}{l}\text { Airports, aviation, chemical } \\
\text { fibber, chemicals, power and heat, } \\
\text { water suppliers, hotels, financial, } \\
\text { iron and steel petrochemicals, } \\
\text { ports, shipping, non-ferrous } \\
\text { metals, building material, paper, } \\
\text { railways, rubber, textiles }\end{array}$ & $\begin{array}{l}\text { Electricity providers, } \\
\text { heating sector, cement, } \\
\text { petrochemicals, other } \\
\text { industrial enterprises, } \\
\text { manufacturers, service } \\
\text { sector, public transport }\end{array}$ & $\begin{array}{l}\text { Power, iron\& steel, } \\
\text { cement, } \\
\text { petrochemicals. } \\
\text { aviation, paper and } \\
\text { white cement }\end{array}$ & $\begin{array}{l}\text { Heat \& electricity } \\
\text { production, iron\& } \\
\text { steel, petrochemicals, } \\
\text { chemicals, oil \&gas } \\
\text { exploration }\end{array}$ & $\begin{array}{l}\text { Power and heat supply, } \\
\text { iron\&steel, non-ferrous metals, } \\
\text { petrochemicals, chemical fibber, } \\
\text { cement, glass and other building } \\
\text { materials, pulp and paper, } \\
\text { ceramics, auto equipment } \\
\text { manufacturing, food, beverage\& } \\
\text { medicine producers. }\end{array}$ & $\begin{array}{l}\text { Power, electrolytic } \\
\text { aluminium, } \\
\text { ferroalloys, calcium } \\
\text { carbide, cement, } \\
\text { caustic soda, and iron } \\
\text { and steel. }\end{array}$ \\
\hline Entities Covered & 635 & 191 & 543 & 184 & 112 & 138 & 242 \\
\hline Contract Ticker & SZA13/14/15/16 & SHEA13/14/15/16 & BEA & GDEA & TJEA & HBEA & CQEA-1 \\
\hline Cap Emissions & $\begin{array}{l}32 \mathrm{Mt}(2014) \\
31 \mathrm{Mt}(2016)\end{array}$ & $\begin{array}{l}160 \mathrm{Mt}(2014) \\
155 \mathrm{Mt}(2016)\end{array}$ & $\begin{array}{l}50 \mathrm{Mt}(2014) \\
46 \mathrm{Mt}(2016)\end{array}$ & $\begin{array}{l}408 \mathrm{Mt}(2014) \\
386 \mathrm{Mt}(2016)\end{array}$ & $\begin{array}{l}160 \mathrm{Mt}(2014) \\
170 \mathrm{Mt}(2016)\end{array}$ & $\begin{array}{l}324 \mathrm{Mt}(2014) \\
253 \mathrm{Mt}(2016)\end{array}$ & $\begin{array}{l}125 \mathrm{Mt}(2014) \\
100 \mathrm{Mt}(2016)\end{array}$ \\
\hline $\begin{array}{l}\text { Compliance } \\
\text { Deadline }\end{array}$ & $\begin{array}{l}\text { June 30, } 2014 \\
\text { June 30, } 2015 \\
\text { June 30, } 2016\end{array}$ & $\begin{array}{l}\text { June 30, } 2014 \\
\text { June 30, } 2015 \\
\text { June 30, } 2016\end{array}$ & $\begin{array}{l}\text { June 15, } 2014 \\
\text { June 15, } 2015 \\
\text { June } 15,2016\end{array}$ & $\begin{array}{l}\text { July 15, } 2014 \\
\text { June 23, } 2015 \\
\text { June 20, } 2016\end{array}$ & $\begin{array}{l}\text { July } 25,2014 \\
\text { July } 10,2015 \\
\text { June } 30,2016\end{array}$ & $\begin{array}{l}\text { July } 29,2015^{*} \\
\text { July } 25,2016\end{array}$ & $\begin{array}{l}\text { June } 20,2015^{*} \\
\text { June } 20,2016\end{array}$ \\
\hline Banking & Yes & Yes & Yes & Yes & Yes & Yes & Yes \\
\hline Borrowing & No & No & No & No & No & No & No \\
\hline Offset Credits & CCERs & CCERs & $\begin{array}{l}\text { CCERs from western } \\
\text { China }\end{array}$ & $\begin{array}{l}\text { CCERs with } \\
\text { limitations }\end{array}$ & $\begin{array}{l}\text { CCERs and } \\
\text { Guangdong forestry } \\
\text { CERs }\end{array}$ & CCERs & CCERs \\
\hline $\begin{array}{l}\text { Percentage of } \\
\text { CCER for offset }\end{array}$ & $10 \%$ & $5 \%$ & $5 \%$ & $10 \%$ & $10 \%$ & $10 \%$ & $8 \%$ \\
\hline $\begin{array}{l}\text { Maximum } \\
\text { Monetary } \\
\text { Penalty }\end{array}$ & $¥ 500,000$ & $¥ 100,000$ & $¥ 50,000$ & $¥ 50,000$ & None & $¥ 150,000$ & $¥ 50,000$ \\
\hline
\end{tabular}




\section{Table 2 Sample periods and number of observations}

Table 2 reports the sample periods and the number of observations. In the Shanghai market, almost no trading activities were recorded in periods from July to September 2014, August to November 2015 and July to November 2016. The Chongqing market is not reported as the percentage of trading days with available trading volume data is less than $5 \%$. The start date indicates the first trading day when the first price observation is recoded by the exchange, this may not be the same with the inception dates.

\begin{tabular}{lrcccc}
\hline Market & Start date & End date & $\begin{array}{c}\text { Total number } \\
\text { of daily observations }\end{array}$ & $\begin{array}{c}\text { Day with no non-zero } \\
\text { trading volume }\end{array}$ & $\begin{array}{c}\% \text { days } \\
\text { with trading }\end{array}$ \\
\hline Shenzhen & $2-$-Oct-13 & 31 -Dec-16 & 813 & 701 & $86 \%$ \\
Shanghai & 26-Nov-13 & 31 -Dec-16 & 760 & 455 & $60 \%$ \\
Beijing & 2-Dec-13 & 31 -Dec-16 & 756 & 521 & $69 \%$ \\
Guangdong & $18-$-Mar-14 & 31 -Dec-16 & 700 & 489 & $70 \%$ \\
Tianjin & 1-Apr-14 & 31 -Dec-16 & 695 & 383 & $55 \%$ \\
Hubei & 2-Apr-14 & 31 -Dec-16 & 696 & 667 & $96 \%$ \\
\hline
\end{tabular}

\section{Table 3 Summary statistics of carbon prices and returns}

Table 3 reports the summary statistics of weekly carbon prices and returns for Beijing, Guangdong, Hubei and Shenzhen pilots. KS denotes the test statistic of the Kolmogorov-Smirnov test for normality. ADF shows the test statistics of an augmented Dickey-Fuller unit root test for stationarity. ${ }^{*}(*)$ indicates that the null hypothesis of the corresponding can be rejected at the 5\% (1\%) confidence level.

\begin{tabular}{|c|c|c|c|c|c|c|c|c|c|}
\hline & Obs & Mean & StDev & Skew. & Kurt. & Min & $\operatorname{Max}$ & $\mathrm{ADF}$ & $\mathrm{KS}$ \\
\hline & & \multicolumn{8}{|c|}{ Beijing - 02/12/2013 - 31/12/2016 } \\
\hline Volume-weighted weekly prices & 148 & 49.744 & 7.034 & 0.163 & 1.784 & 33.382 & 74.350 & -2.765 & $0.164 * *$ \\
\hline \multirow[t]{2}{*}{ Weekly returns } & 147 & 0.002 & 0.078 & 0.939 & 3.924 & -0.206 & 0.343 & $-7.489 * *$ & $0.181 * *$ \\
\hline & & \multicolumn{8}{|c|}{ Guangdong - 18/03/2014 - 31/12/2016 } \\
\hline Volume-weighted weekly prices & 139 & 24.978 & 17.535 & 1.484 & 0.839 & 8.417 & 73.117 & -2.056 & $0.252 * *$ \\
\hline \multirow[t]{2}{*}{ Weekly returns } & 138 & -0.011 & 0.122 & -0.355 & 1.441 & -0.459 & 0.290 & $-9.941 * *$ & $0.092 * *$ \\
\hline & & \multicolumn{8}{|c|}{ Hubei - 02/04/2014 - 31/12/2016 } \\
\hline Volume-weighted weekly prices & 143 & 21.847 & 3.797 & -0.973 & -0.251 & 10.655 & 27.438 & -1.444 & $0.225 * *$ \\
\hline \multirow[t]{2}{*}{ Weekly returns } & 142 & -0.001 & 0.053 & -1.350 & 12.449 & -0.324 & 0.202 & $-10.061 * *$ & $0.186^{* *}$ \\
\hline & & \multicolumn{8}{|c|}{ Shenzhen - 02/10/2013 - 31/12/2016 } \\
\hline Volume-weighted weekly prices & 168 & 43.159 & 14.181 & 1.274 & 1.201 & 22.001 & 83.517 & -2.556 & $0.233 * *$ \\
\hline Weekly returns & 167 & -0.007 & 0.095 & 0.035 & 1.544 & -0.272 & 0.320 & $-12.223 * *$ & $0.094 * *$ \\
\hline
\end{tabular}




\section{Table 4 Weekly trading volume}

This table reports a basic summary of weekly trading volume (in tons) recorded for Beijing, Guangdong, Hubei and Shenzhen pilots. $\mathrm{Q}_{25 \%}$ and $\mathrm{Q}_{75 \%}$ represent the $25 \%$ and $75 \%$ quintile values, respectively.

\begin{tabular}{lrrrrrrr}
\hline & Mean & StDev & Min & Q $_{25 \%}$ & Median & Q $_{75 \%}$ & Max \\
\hline Beijing & 29,463 & 67,705 & 1 & 816 & 4,950 & 19,670 & 465,897 \\
Guangdong & 144,984 & 291,548 & 2 & 1,193 & 8,768 & 181,712 & $1,892,847$ \\
Hubei & 217,645 & 362,978 & 2,622 & 65,558 & 129,047 & 545,063 & 362,978 \\
Shenzhen & 77,599 & 410,546 & 1 & 3,040 & 12,002 & 42,300 & $4,000,061$ \\
\hline
\end{tabular}




\section{Table 5 Summary statistics of explanatory variables}

Table 5 reports the summary statistics of weekly log differences of explanatory variables. ADF denotes the test statistics of an augmented Dickey-Fuller unit root test for stationarity. All tests are rejected at the $1 \%$ confidence level. The SSE (SZSE) index tracks the performance of all A-shares and B-shares listed on the Shanghai (Shenzhen) Stock Exchange. Energy, materials, industrials and utilities indices denote the respective sub-sector indices of the Shanghai Composite Index. Bond yield denotes the 10-year Chinese government bond yields, quoted based on the bid side of the market. Chinese coal denotes the thermal coal Qinhuangdao $5500 \mathrm{kcal} / \mathrm{kg}$ spot price and the Australian coal denotes the Australia Newcastle Port Thermal Coal 6000 $\mathrm{kcal} / \mathrm{kg}$ FOB spot price. Steel denotes the hot rolled steel $3 \mathrm{~mm}$ export price in Shanghai. Iron ore aggregates the total inventory of iron ore at all Chinese ports. LNG Asia denotes the Liquid Natural Gas price FOB in Asia USD/Mmbtu. NYMEX Gas denotes the S\&P GSCI natural gas excess return index. JCC represents the Crude Oil Cocktail Japan Customs-Cleared Crude cost, insurance and freight import USD/barrel. Daqing and NYMEX crude denote Chinese domestic and international crude oil price, respectively. China VIX denotes the AlphaShares Chinese volatility index which measures the implied volatility of options on the FTSE Xinhua China 25 and Hang Seng indices. OVX denotes the CBOE crude oil volatility index which measures the market expectation of 30-day volatility of crude oil prices. China sentiment measures the inflow/outflow of CSOP China related ETFs which have an AUM of larger than CNY 200Million. All non-Chinese data are converted to CNY.

\begin{tabular}{lrrrrrr}
\hline & $\begin{array}{r}\text { Bloomberg/ } \\
\text { Reuters Ticker }\end{array}$ & Mean & StDev & Min & Max & ADF \\
\hline Stock Indices & SHCOMP & 0.0020 & 0.0405 & -0.2594 & 0.1056 & -9.125 \\
SSE Index & SZCOMP & 0.0035 & 0.0495 & -0.2703 & 0.1080 & -8.926 \\
SZSE Index & SH000032 & -0.0004 & 0.0483 & -0.3256 & 0.1282 & -10.692 \\
Energy Index & SH000033 & 0.0010 & 0.0517 & -0.3126 & 0.1193 & -9.921 \\
Materials Index & SH000034 & 0.0026 & 0.0532 & -0.3134 & 0.1292 & -9.498 \\
Industrials Index & SH000035 & 0.0021 & 0.0453 & -0.2602 & 0.1292 & -9.334 \\
Utilities Index & GCNY10YR & -0.0015 & 0.0211 & -0.0700 & 0.0529 & -9.167 \\
Bond Yield & & & & & & \\
& & & & & & \\
Energies \& Metals & COASQI55 & 0.0010 & 0.0201 & -0.0953 & 0.0820 & -5.078 \\
Chinese Coal & COASE60 & 0.0014 & 0.0324 & -0.1088 & 0.1173 & -6.547 \\
Australian Coal & CSPWHSE & 0.0005 & 0.0366 & -0.2056 & 0.2827 & -7.148 \\
Steel & CIOITAL & 0.0022 & 0.0181 & -0.0620 & 0.0583 & -7.546 \\
Iron Ore & S922MU & -0.0023 & 0.0494 & -0.1788 & 0.1701 & -7.179 \\
LNG Asia & SPGSNGP & -0.0030 & 0.0542 & -0.1895 & 0.1840 & -9.679 \\
NYMEX Gas & CRUDJCC & -0.0016 & 0.0476 & -0.3566 & 0.1480 & -8.963 \\
JCC & APCRDAQG & -0.0025 & 0.0612 & -0.1369 & 0.1557 & -7.558 \\
Daqing Crude & S74157 & -0.0042 & 0.0487 & -0.3566 & 0.1480 & -8.228 \\
Brent Crude & & & & &
\end{tabular}

Market Sentiment

China VIX
OVX

China Sentiment

$\begin{array}{rrrrrr}\text { ASCHCHIX } & 0.0003 & 0.1117 & -0.4704 & 0.4780 & -11.019 \\ \text { OVX } & 0.0022 & 0.0954 & -0.2107 & 0.3612 & -8.885 \\ \text { CSOPSI } & -0.0011 & 0.0550 & -0.2751 & 0.2087 & -7.304\end{array}$




\section{Table 6 Cross-correlations}

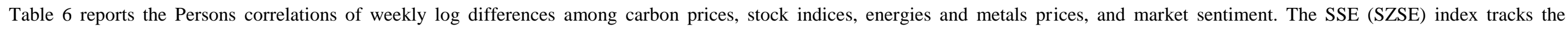

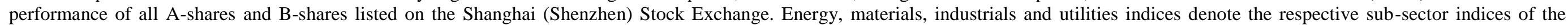

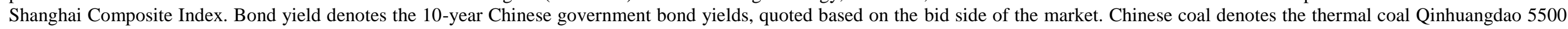

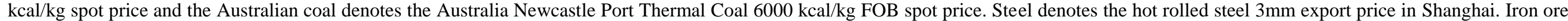

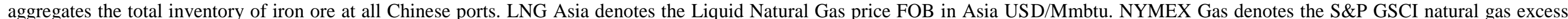

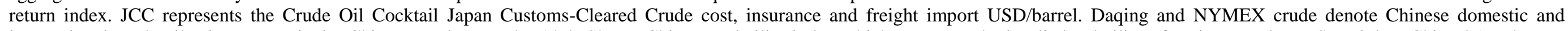

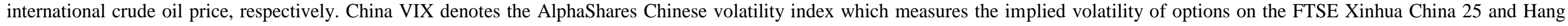

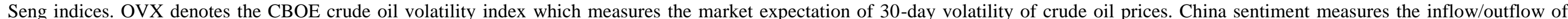

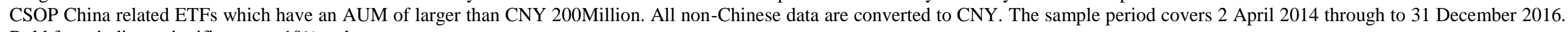
Bold fonts indicate significance at $10 \%$ or better.

\begin{tabular}{|c|c|c|c|c|c|c|c|c|c|c|c|c|c|c|c|c|c|c|c|c|c|}
\hline & Beijing & Guangdong & Hubei & Shenzhen & $\begin{array}{l}\text { SSE } \\
\text { Index }\end{array}$ & $\begin{array}{l}\text { SZSE } \\
\text { Index }\end{array}$ & $\begin{array}{r}\text { Energy } \\
\text { Index } \\
\end{array}$ & $\begin{array}{r}\text { Material } \\
\text { Index } \\
\end{array}$ & $\begin{array}{r}\text { Industria } \\
\text { Inde } \\
\end{array}$ & $\begin{array}{r}\text { Utilities } \\
\text { Index }\end{array}$ & $\begin{array}{l}\text { Bond } \\
\text { Yield } \\
\end{array}$ & $\begin{array}{l}\text { CHN } \\
\text { Coal } \\
\end{array}$ & $\begin{array}{l}\text { AUS } \\
\text { Coal }\end{array}$ & Steel & $\begin{array}{l}\text { Iron } \\
\text { Ore }\end{array}$ & $\begin{array}{l}\text { LNG } \\
\text { Asia }\end{array}$ & $\begin{array}{l}\text { NYMEX } \\
\text { Gas }\end{array}$ & $\mathrm{JCC}$ & $\begin{array}{l}\text { Brent } \\
\text { Crude }\end{array}$ & $\begin{array}{l}\text { China } \\
\text { VIX }\end{array}$ & ovx \\
\hline \multicolumn{22}{|c|}{ Panel A: Carbon Prices } \\
\hline Guangdong & 0.031 & & & & & & & & & & & & & & & & & & & & \\
\hline Hubei & -0.066 & -0.126 & & & & & & & & & & & & & & & & & & & \\
\hline Shenzhen & 0.130 & -0.057 & 0.104 & & & & & & & & & & & & & & & & & & \\
\hline \multicolumn{22}{|c|}{ Panel B: Stock Indices } \\
\hline SSE Index & -0.026 & -0.014 & 0.089 & 0.160 & & & & & & & & & & & & & & & & & \\
\hline SZSE Index & -0.074 & -0.072 & 0.054 & 0.196 & 0.892 & & & & & & & & & & & & & & & & \\
\hline Energy Index & -0.014 & 0.006 & 0.101 & 0.178 & 0.927 & 0.786 & & & & & & & & & & & & & & & \\
\hline Materials Index & -0.026 & -0.016 & 0.108 & 0.216 & 0.938 & 0.893 & 0.937 & & & & & & & & & & & & & & \\
\hline Industrials Index & 0.025 & 0.016 & 0.110 & 0.129 & 0.948 & 0.832 & 0.884 & 0.903 & & & & & & & & & & & & & \\
\hline Utilities Index & 0.018 & 0.019 & 0.125 & 0.150 & 0.899 & 0.819 & 0.884 & 0.919 & 0.906 & & & & & & & & & & & & \\
\hline Bond Yield & 0.016 & 0.081 & 0.085 & 0.052 & 0.118 & 0.147 & 0.096 & 0.144 & 0.112 & 0.107 & & & & & & & & & & & \\
\hline \multicolumn{22}{|c|}{ Panel C: Energies \& Metals } \\
\hline Chinese Coal & 0.020 & -0.030 & 0.009 & -0.019 & -0.082 & -0.101 & -0.043 & -0.046 & -0.089 & -0.072 & -0.055 & & & & & & & & & & \\
\hline Australian Coal & -0.008 & 0.082 & -0.086 & -0.001 & -0.075 & -0.007 & -0.024 & -0.006 & -0.083 & -0.013 & -0.139 & 0.466 & & & & & & & & & \\
\hline Steel & 0.059 & -0.086 & -0.045 & 0.034 & 0.074 & -0.008 & 0.113 & 0.102 & 0.057 & 0.042 & 0.127 & 0.185 & -0.035 & & & & & & & & \\
\hline Iron Ore & 0.047 & -0.138 & -0.030 & 0.080 & -0.115 & -0.122 & -0.084 & -0.097 & -0.101 & -0.176 & 0.014 & 0.137 & 0.025 & 0.022 & & & & & & & \\
\hline LNG Asia & 0.045 & -0.013 & -0.044 & 0.050 & -0.008 & 0.014 & 0.009 & -0.055 & -0.034 & 0.011 & 0.078 & 0.086 & 0.097 & -0.020 & -0.060 & & & & & & \\
\hline NYMEX Gas & 0.078 & 0.018 & 0.213 & -0.196 & -0.018 & 0.002 & -0.043 & -0.052 & 0.000 & -0.038 & 0.017 & -0.058 & -0.090 & 0.037 & -0.067 & 0.168 & & & & & \\
\hline JCC & 0.036 & 0.040 & -0.068 & 0.027 & 0.042 & 0.106 & -0.032 & -0.007 & 0.065 & 0.031 & 0.035 & -0.002 & -0.065 & -0.003 & -0.001 & 0.221 & 0.216 & & & & \\
\hline Brent Crude & 0.072 & 0.050 & 0.008 & 0.047 & 0.249 & 0.266 & 0.279 & 0.281 & 0.249 & 0.269 & 0.088 & -0.026 & 0.160 & 0.208 & 0.014 & -0.101 & -0.084 & -0.134 & & & \\
\hline \multicolumn{22}{|c|}{ Panel D: Market Sentiment } \\
\hline China VIX & 0.056 & -0.009 & -0.016 & -0.061 & -0.307 & -0.425 & -0.277 & -0.379 & -0.327 & -0.388 & -0.122 & 0.012 & -0.085 & 0.105 & 0.104 & 0.104 & -0.025 & -0.008 & -0.208 & & \\
\hline OVX & 0.053 & -0.075 & 0.098 & -0.061 & -0.157 & -0.203 & -0.192 & -0.170 & -0.152 & -0.203 & 0.013 & 0.198 & -0.004 & 0.048 & 0.091 & -0.099 & -0.033 & 0.097 & -0.249 & 0.426 & \\
\hline China Sentiment & 0.040 & -0.004 & -0.117 & -0.070 & -0.292 & -0.198 & -0.269 & -0.277 & -0.363 & -0.305 & -0.112 & 0.026 & 0.004 & 0.160 & 0.106 & 0.015 & 0.052 & 0.057 & 0.095 & 0.058 & -0.012 \\
\hline
\end{tabular}




\section{Table 7 Univariate regressions at weekly frequency}

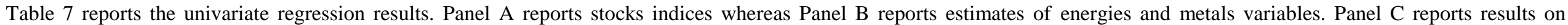

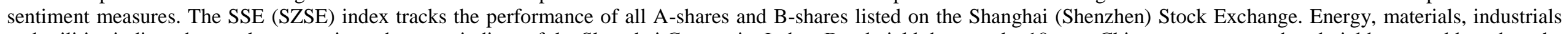

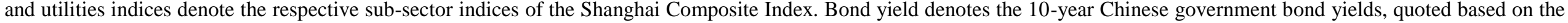

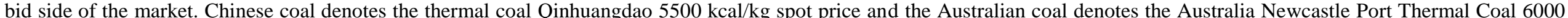

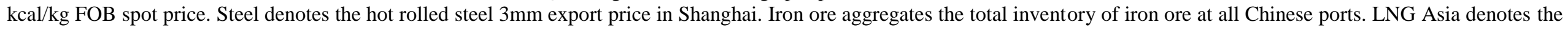

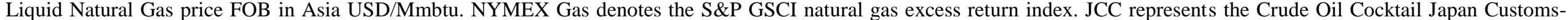

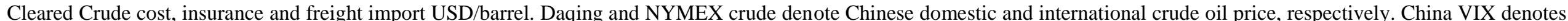

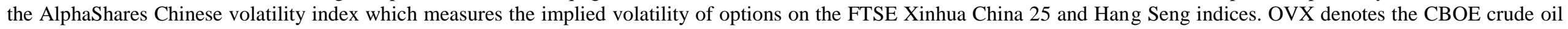

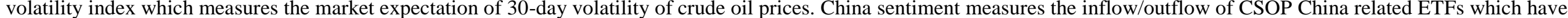

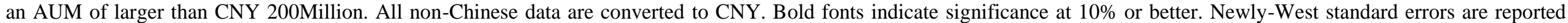
throughout.

\begin{tabular}{|c|c|c|c|c|c|c|c|c|c|c|c|c|c|c|c|c|}
\hline \multirow[t]{2}{*}{ IVs } & \multicolumn{4}{|c|}{ Beijing } & \multicolumn{4}{|c|}{ Guangdong } & \multicolumn{4}{|c|}{ Hubei } & \multicolumn{4}{|c|}{ Shenzhen } \\
\hline & Coefficient & StdErr & $t$-stats & $R^{2}$ & Coefficient & StdErr & $t$-stats & $R^{2}$ & Coefficient & StdErr & $t$-stats & $R^{2}$ & Coefficient & StdErr & $t$-stats & $R^{2}$ \\
\hline \multicolumn{17}{|c|}{ Panel A: Stock indices } \\
\hline SSE Index & 0.100 & 0.165 & 0.61 & 0.003 & 0.015 & 0.184 & 0.08 & 0.000 & 0.103 & 0.082 & 1.26 & 0.008 & 0.231 & 0.117 & 1.98 & 0.010 \\
\hline SZSE Index & 0.011 & 0.180 & 0.06 & 0.000 & -0.119 & 0.165 & -0.72 & 0.003 & 0.052 & 0.067 & 0.78 & 0.003 & 0.262 & 0.115 & 2.27 & 0.020 \\
\hline Energy Index & 0.094 & 0.098 & 0.96 & 0.004 & 0.062 & 0.161 & 0.38 & 0.001 & 0.093 & 0.071 & 1.31 & 0.009 & 0.248 & 0.107 & 2.33 & 0.017 \\
\hline Materials Index & 0.092 & 0.113 & 0.82 & 0.004 & 0.019 & 0.134 & 0.14 & 0.000 & 0.094 & 0.059 & 1.60 & 0.011 & 0.285 & 0.101 & 2.81 & 0.025 \\
\hline Industrials Index & 0.127 & 0.111 & 1.14 & 0.008 & 0.053 & 0.165 & 0.32 & 0.001 & 0.093 & 0.062 & 1.50 & 0.011 & 0.136 & 0.134 & 1.02 & 0.006 \\
\hline Utilities Index & 0.151 & 0.118 & 1.28 & 0.008 & 0.076 & 0.175 & 0.44 & 0.001 & 0.124 & 0.061 & 2.04 & 0.014 & 0.235 & 0.157 & 1.50 & 0.013 \\
\hline Bond Yield & -0.052 & 0.250 & -0.21 & 0.000 & 0.303 & 0.417 & 0.73 & 0.003 & 0.189 & 0.162 & 1.16 & 0.007 & 0.025 & 0.318 & 0.08 & 0.000 \\
\hline \multicolumn{17}{|c|}{ Panel B: Energies \& Metals } \\
\hline Chinese Coal & -0.069 & 0.142 & -0.49 & 0.000 & -0.239 & 0.486 & -0.49 & 0.001 & 0.055 & 0.265 & 0.21 & 0.000 & 0.001 & 0.337 & 0.00 & 0.000 \\
\hline Australian Coal & 0.056 & 0.162 & 0.34 & 0.001 & 0.338 & 0.372 & 0.91 & 0.010 & -0.107 & 0.113 & -0.94 & 0.006 & -0.052 & 0.155 & -0.33 & 0.000 \\
\hline Steel & 0.051 & 0.142 & 0.36 & 0.001 & -0.246 & 0.277 & -0.89 & 0.007 & -0.057 & 0.064 & -0.88 & 0.002 & 0.050 & 0.156 & 0.32 & 0.000 \\
\hline Iron Ore & 0.433 & 0.411 & 1.05 & 0.009 & -0.771 & 0.556 & -1.39 & 0.013 & -0.026 & 0.220 & -0.12 & 0.000 & 0.511 & 0.285 & 1.79 & 0.010 \\
\hline LNG Asia & 0.080 & 0.107 & 0.75 & 0.003 & 0.052 & 0.099 & 0.52 & 0.001 & -0.065 & 0.062 & -1.05 & 0.005 & -0.020 & 0.170 & -0.12 & 0.000 \\
\hline NYMEX Gas & 0.120 & 0.143 & 0.84 & 0.005 & 0.053 & 0.157 & 0.34 & 0.001 & 0.057 & 0.052 & 1.11 & 0.005 & 0.064 & 0.102 & 0.63 & 0.002 \\
\hline $\mathrm{JCC}$ & -0.056 & 0.137 & -0.41 & 0.002 & 0.136 & 0.174 & 0.78 & 0.003 & 0.003 & 0.062 & 0.04 & 0.000 & 0.066 & 0.121 & 0.54 & 0.001 \\
\hline Daqing Crude & 0.092 & 0.180 & 0.51 & 0.003 & 0.059 & 0.221 & 0.27 & 0.001 & -0.023 & 0.079 & -0.28 & 0.001 & 0.062 & 0.107 & 0.58 & 0.001 \\
\hline Brent Crude & 0.056 & 0.108 & 0.52 & 0.002 & 0.009 & 0.146 & 0.06 & 0.000 & 0.172 & 0.071 & 2.44 & 0.037 & -0.232 & 0.118 & -1.97 & 0.020 \\
\hline \multicolumn{17}{|c|}{ Panel C: Market Sentiment } \\
\hline China VIX & -0.040 & 0.059 & -0.67 & 0.004 & -0.021 & 0.056 & -0.38 & 0.001 & -0.005 & 0.041 & -0.13 & 0.000 & -0.049 & 0.065 & -0.77 & 0.003 \\
\hline OVX & 0.001 & 0.055 & 0.02 & 0.000 & -0.111 & 0.101 & -1.10 & 0.009 & 0.039 & 0.053 & 0.73 & 0.006 & -0.047 & 0.060 & -0.78 & 0.002 \\
\hline China Sentiment & -0.054 & 0.102 & -0.52 & 0.002 & 0.002 & 0.215 & 0.01 & 0.000 & -0.069 & 0.064 & -1.08 & 0.007 & -0.075 & 0.084 & -0.90 & 0.002 \\
\hline
\end{tabular}




\section{Table 8 Multivariate regressions at weekly frequency}

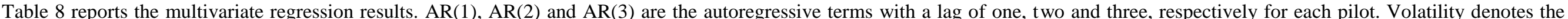

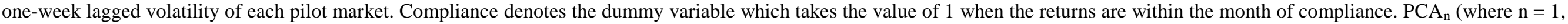

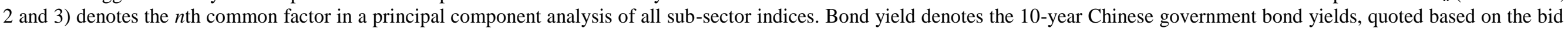

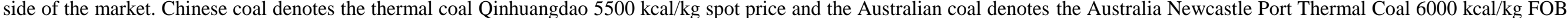

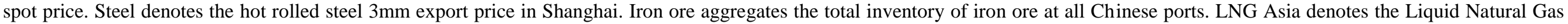

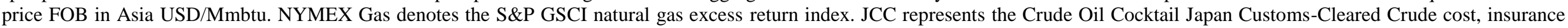

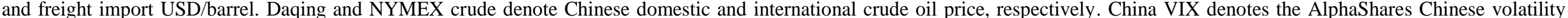

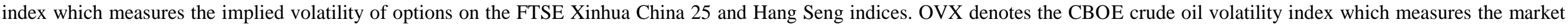

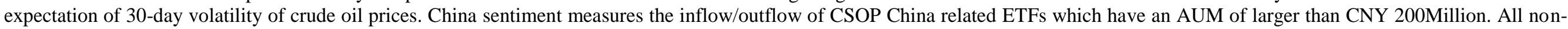

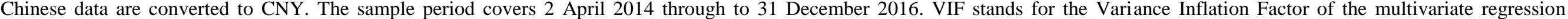
components. Bold fonts indicate significance at $10 \%$ or better. Newly-West standard errors are reported throughout.

\begin{tabular}{|c|c|c|c|c|c|c|c|c|c|c|c|c|c|c|c|c|}
\hline \multirow[t]{2}{*}{ IVs } & \multicolumn{4}{|c|}{ Beijing } & \multicolumn{4}{|c|}{ Guangdong } & \multicolumn{4}{|c|}{ Hubei } & \multicolumn{4}{|c|}{ Shenzhen } \\
\hline & Coefficient & StdErr & Prob & VIF & Coefficient & StdErr & Prob & VIF & Coefficient & StdErr & Prob & VIF & Coefficient & StdErr & Prob & VIF \\
\hline \multicolumn{17}{|c|}{ Panel A: Regressions with China-based variables } \\
\hline Intercept & 0.007 & 0.006 & 0.269 & 0.000 & 0.000 & 0.010 & 0.965 & 0.000 & -0.002 & 0.003 & 0.590 & 0.000 & -0.014 & 0.008 & 0.089 & 0.000 \\
\hline $\operatorname{AR}(1)$ & -0.265 & 0.104 & 0.012 & 1.061 & 0.035 & 0.079 & 0.660 & 1.382 & 0.083 & 0.127 & 0.517 & 1.230 & -0.246 & 0.075 & 0.001 & 1.089 \\
\hline $\mathrm{AR}(2)$ & & & & & -0.266 & 0.094 & 0.006 & 1.114 & -0.263 & 0.153 & 0.088 & 1.100 & -0.347 & 0.089 & 0.000 & 1.121 \\
\hline $\operatorname{AR}(3)$ & & & & & -0.260 & 0.078 & 0.001 & 1.325 & & & & & & & & \\
\hline Volatility & -0.975 & 0.427 & 0.024 & 1.091 & -0.271 & 0.269 & 0.316 & 1.229 & 0.640 & 0.476 & 0.182 & 1.349 & 0.410 & 0.499 & 0.413 & 1.173 \\
\hline Compliance & -0.008 & 0.016 & 0.638 & 1.118 & -0.127 & 0.043 & 0.004 & 1.205 & -0.032 & 0.040 & 0.429 & 1.260 & -0.009 & 0.015 & 0.559 & 1.070 \\
\hline $\mathrm{PCA}_{1}$ & 0.001 & 0.005 & 0.918 & 1.101 & 0.016 & 0.009 & 0.098 & 1.159 & 0.001 & 0.004 & 0.689 & 1.105 & 0.010 & 0.006 & 0.088 & 1.108 \\
\hline $\mathrm{PCA}_{2}$ & -0.009 & 0.009 & 0.308 & 1.200 & -0.026 & 0.009 & 0.004 & 1.229 & -0.001 & 0.003 & 0.791 & 1.189 & 0.017 & 0.006 & 0.005 & 1.193 \\
\hline $\mathrm{PCA}_{3}$ & 0.006 & 0.006 & 0.332 & 1.252 & 0.007 & 0.012 & 0.580 & 1.398 & 0.003 & 0.004 & 0.407 & 1.183 & 0.006 & 0.009 & 0.555 & 1.161 \\
\hline Bond Yield & -0.069 & 0.268 & 0.796 & 1.080 & 0.432 & 0.461 & 0.350 & 1.255 & 0.170 & 0.157 & 0.282 & 1.116 & -0.180 & 0.308 & 0.559 & 1.065 \\
\hline Chinese Coal & -0.066 & 0.209 & 0.754 & 1.062 & -0.041 & 0.548 & 0.940 & 1.119 & 0.035 & 0.217 & 0.872 & 1.127 & -0.102 & 0.335 & 0.760 & 1.068 \\
\hline Steel & -0.068 & 0.179 & 0.704 & 1.208 & -0.384 & 0.213 & 0.075 & 1.211 & -0.061 & 0.083 & 0.462 & 1.252 & 0.074 & 0.147 & 0.614 & 1.161 \\
\hline Iron ore & 0.457 & 0.364 & 0.212 & 1.045 & -0.877 & 0.493 & 0.078 & 1.068 & 0.041 & 0.208 & 0.846 & 1.091 & 0.465 & 0.283 & 0.103 & 1.079 \\
\hline JCC & 0.137 & 0.117 & 0.243 & 1.081 & 0.244 & 0.142 & 0.090 & 1.169 & -0.064 & 0.060 & 0.291 & 1.068 & -0.039 & 0.144 & 0.789 & 1.061 \\
\hline LNG Asia & 0.077 & 0.156 & 0.624 & 1.057 & 0.073 & 0.199 & 0.712 & 1.071 & -0.021 & 0.074 & 0.778 & 1.072 & 0.001 & 0.134 & 0.997 & 1.087 \\
\hline China VIX & -0.072 & 0.048 & 0.131 & 1.199 & -0.050 & 0.086 & 0.560 & 1.242 & 0.017 & 0.035 & 0.624 & 1.222 & 0.064 & 0.077 & 0.406 & 1.304 \\
\hline China Sentiment & -0.013 & 0.099 & 0.899 & 1.242 & 0.222 & 0.217 & 0.308 & 1.302 & -0.047 & 0.067 & 0.482 & 1.272 & -0.068 & 0.133 & 0.609 & 1.152 \\
\hline $\operatorname{adj} R^{2}$ & 0.067 & & & & 0.138 & & & & 0.023 & & & & 0.143 & & & \\
\hline
\end{tabular}


Continue on next page

Panel B: Regressions with China and International-based variables

\begin{tabular}{lrrrr} 
Intercept & 0.008 & 0.006 & 0.231 & 0.000 \\
AR(1) & $\mathbf{- 0 . 2 5 7}$ & 0.102 & 0.013 & 1.087 \\
AR(2) & & & & \\
AR(3) & & & & \\
Volatility & $\mathbf{- 0 . 9 9 6}$ & 0.434 & 0.023 & 1.102 \\
Compliance & -0.008 & 0.016 & 0.640 & 1.122 \\
PCA $_{1}$ & 0.000 & 0.005 & 0.975 & 1.158 \\
PCA $_{2}$ & -0.009 & 0.009 & 0.282 & 1.209 \\
PCA $_{3}$ & 0.005 & 0.006 & 0.372 & 1.314 \\
Bond Yield & -0.085 & 0.264 & 0.749 & 1.102 \\
Chinese Coal & -0.086 & 0.218 & 0.696 & 1.234 \\
Australian Coal & 0.043 & 0.170 & 0.803 & 1.329 \\
Steel & -0.090 & 0.176 & 0.608 & 1.252 \\
Iron Ore & 0.443 & 0.366 & 0.229 & 1.059 \\
JCC & 0.147 & 0.117 & 0.211 & 1.157 \\
Brent Crude & 0.122 & 0.170 & 0.473 & 1.357 \\
LNG Asia & 0.085 & 0.159 & 0.595 & 1.150 \\
NYMEX Gas & 0.005 & 0.095 & 0.958 & 1.119 \\
China VIX & -0.071 & 0.048 & 0.137 & 1.464 \\
OVX & 0.024 & 0.064 & 0.708 & 1.394 \\
China Sentiment & -0.024 & 0.102 & 0.811 & 1.281 \\
adj $R^{2}$ & 0.045 & & & \\
adj $R^{2}$ without AR & -0.017 & & & \\
\hline
\end{tabular}

$\begin{array}{rlll}0.003 & 0.010 & 0.810 & 0.000 \\ 0.039 & 0.082 & 0.634 & 1.402 \\ \mathbf{- 0 . 2 7 4} & 0.103 & 0.009 & 1.220 \\ \mathbf{- 0 . 2 6 5} & 0.082 & 0.002 & 1.353 \\ -0.425 & 0.293 & 0.150 & 1.331 \\ -0.129 & 0.045 & 0.005 & 1.226 \\ 0.014 & 0.010 & 0.165 & 1.186 \\ \mathbf{- 0 . 0 2 6} & 0.009 & 0.003 & 1.242 \\ 0.009 & 0.013 & 0.515 & 1.504 \\ 0.430 & 0.477 & 0.369 & 1.284 \\ 0.165 & 0.576 & 0.775 & 1.460 \\ 0.029 & 0.355 & 0.936 & 1.587 \\ \mathbf{- 0 . 4 1 5} & 0.210 & 0.050 & 1.267 \\ \mathbf{- 0 . 9 8 5} & 0.472 & 0.039 & 1.086 \\ \mathbf{0 . 3 2 9} & 0.152 & 0.032 & 1.261 \\ 0.082 & 0.204 & 0.688 & 1.406 \\ 0.029 & 0.219 & 0.894 & 1.188 \\ -0.093 & 0.138 & 0.500 & 1.159 \\ 0.040 & 0.095 & 0.677 & 1.601 \\ \mathbf{- 0 . 2 0 8} & 0.114 & 0.072 & 1.477 \\ 0.222 & 0.226 & 0.328 & 1.373 \\ 0.137 & & & \\ 0.003 & & & \end{array}$

$\begin{array}{rlll}-0.001 & 0.003 & 0.742 & 0.000 \\ 0.111 & 0.131 & 0.398 & 1.250 \\ \mathbf{- 0 . 2 4 1} & 0.142 & 0.092 & 1.128 \\ & & & \\ 0.737 & 0.465 & 0.116 & 1.372 \\ -0.032 & 0.039 & 0.409 & 1.306 \\ 0.002 & 0.004 & 0.542 & 1.153 \\ 0.000 & 0.004 & 0.930 & 1.202 \\ 0.002 & 0.003 & 0.651 & 1.239 \\ 0.133 & 0.147 & 0.370 & 1.138 \\ 0.039 & 0.244 & 0.872 & 1.458 \\ -0.048 & 0.112 & 0.670 & 1.457 \\ -0.083 & 0.084 & 0.323 & 1.319 \\ 0.138 & 0.201 & 0.495 & 1.112 \\ \mathbf{- 0 . 1 2 1} & 0.059 & 0.043 & 1.154 \\ 0.027 & 0.075 & 0.718 & 1.345 \\ -0.038 & 0.078 & 0.633 & 1.194 \\ \mathbf{0 . 2 0 7} & 0.070 & 0.004 & 1.156 \\ 0.001 & 0.038 & 0.981 & 1.565 \\ 0.055 & 0.054 & 0.313 & 1.476 \\ -0.066 & 0.062 & 0.292 & 1.305 \\ 0.058 & & & \\ -0.008 & & & \end{array}$

\begin{tabular}{rrrr}
-0.014 & 0.008 & 0.079 & 0.000 \\
$\mathbf{- 0 . 2 5 0}$ & 0.073 & 0.001 & 1.096 \\
$\mathbf{- 0 . 3 3 9}$ & 0.088 & 0.000 & 1.136 \\
& & & \\
0.429 & 0.498 & 0.391 & 1.214 \\
-0.008 & 0.015 & 0.624 & 1.073 \\
0.008 & 0.006 & 0.183 & 1.169 \\
$\mathbf{0 . 0 1 7}$ & 0.006 & 0.007 & 1.205 \\
0.005 & 0.010 & 0.596 & 1.181 \\
-0.168 & 0.310 & 0.588 & 1.090 \\
-0.009 & 0.332 & 0.978 & 1.252 \\
-0.099 & 0.193 & 0.608 & 1.294 \\
0.064 & 0.147 & 0.663 & 1.207 \\
0.398 & 0.299 & 0.185 & 1.099 \\
0.002 & 0.153 & 0.990 & 1.139 \\
0.060 & 0.132 & 0.653 & 1.341 \\
0.027 & 0.139 & 0.845 & 1.206 \\
-0.196 & 0.123 & 0.113 & 1.127 \\
0.077 & 0.083 & 0.354 & 1.600 \\
-0.024 & 0.070 & 0.734 & 1.401 \\
-0.065 & 0.131 & 0.622 & 1.172 \\
0.136 & & & \\
-0.024 & & & \\
\hline & & &
\end{tabular}


Figure 1 Returns autocorrelation structure
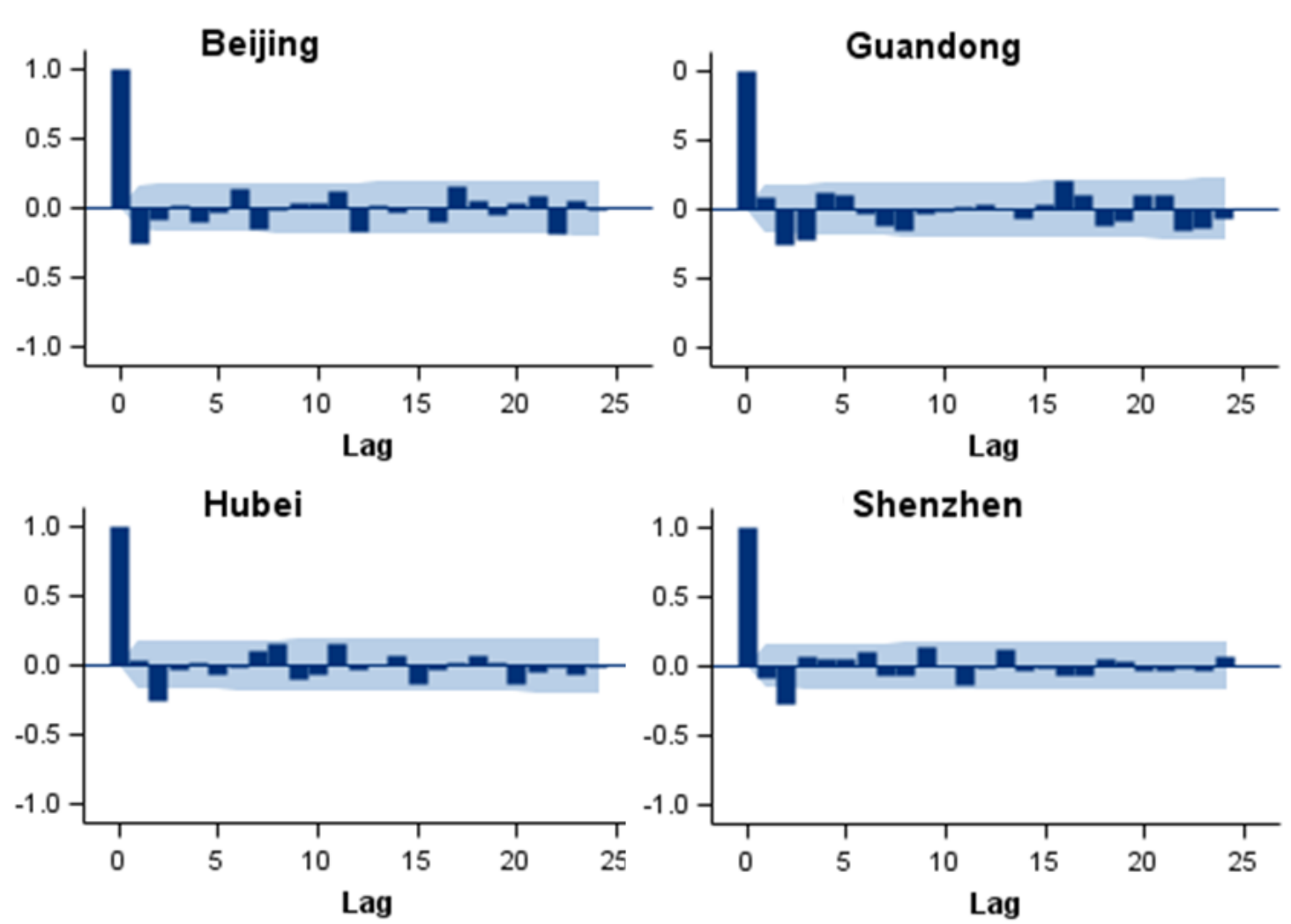

Notes: using a lag length of up to 25, this figure illustrates the autocorrelation structure of carbon allowance returns in the Beijing, Guangdong, Hubei and Shenzhen pilots, respectively. 
Figure 2 Macroeconomic and financial variables
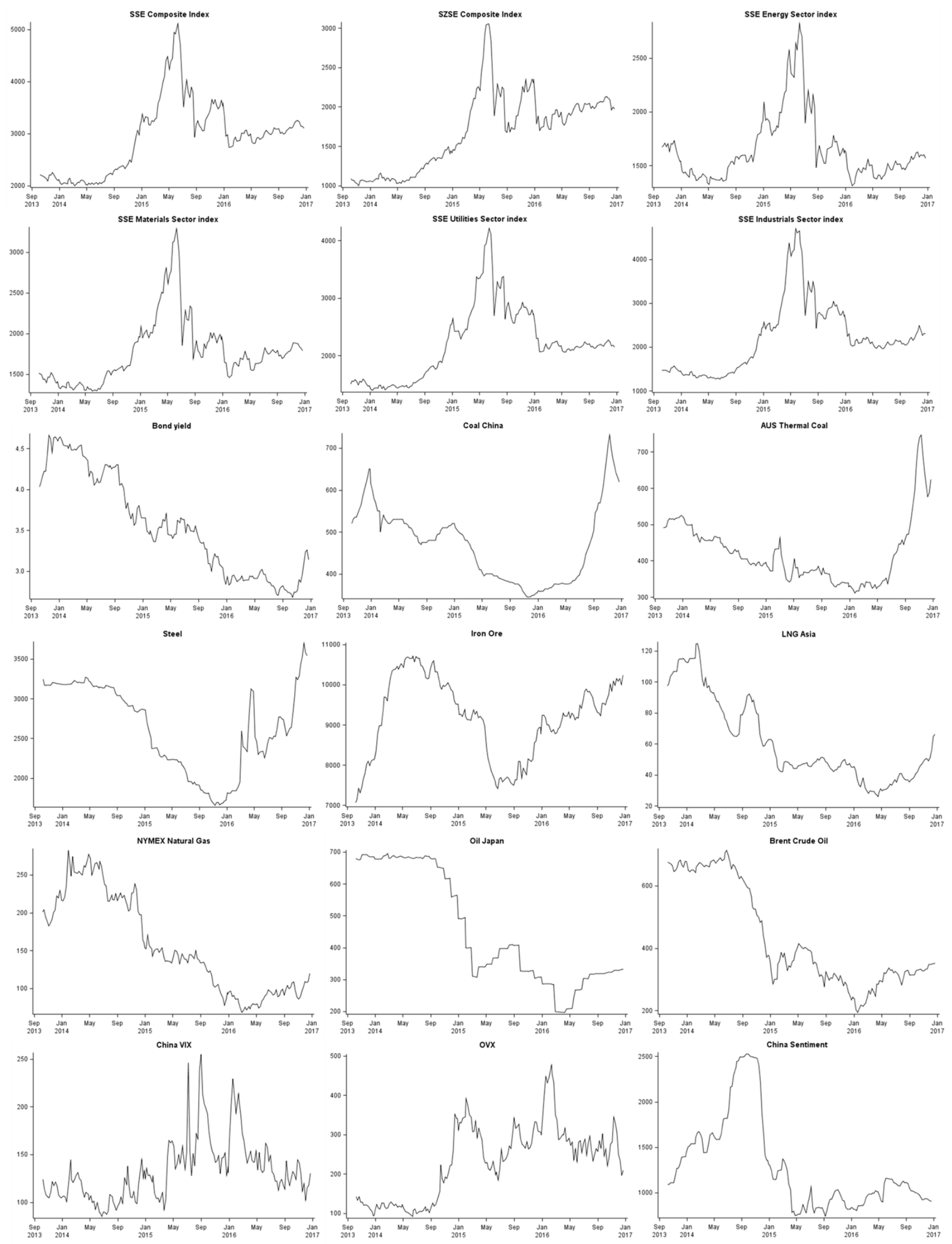

Notes: this figure depicts the movement of all explanatory variables employed in this study. 
Figure 3 Daily carbon prices, returns and trading volumes
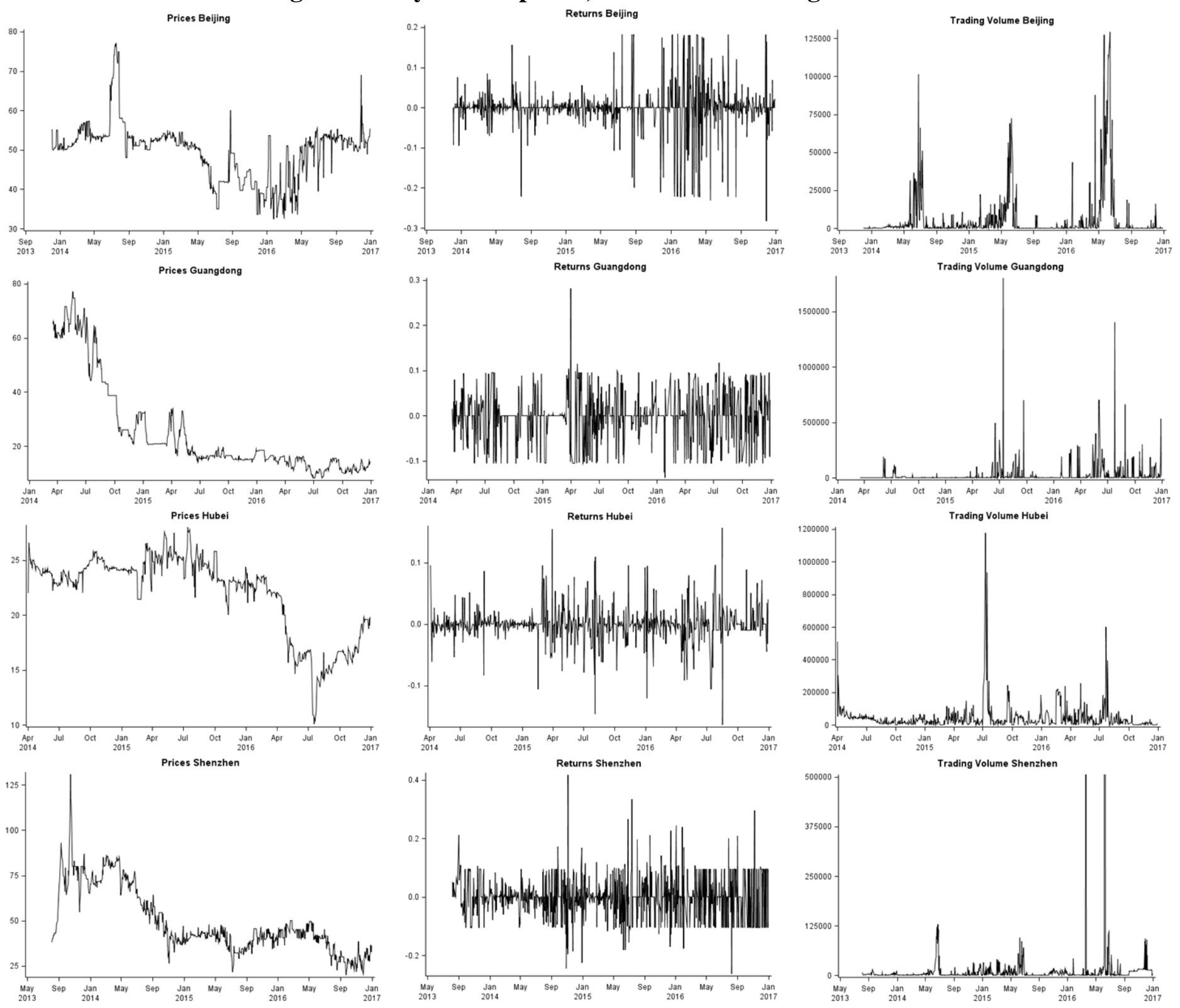

Notes: this figure depicts the daily prices, returns and trading volumes of carbon allowance in the Beijing, Guangdong, Hubei and Shenzhen pilots, respectively. The unit scales are not normalised for clearer observations on the dynamics. The Beijing and Shenzhen pilot data start in December and October of 2013, respectively. The Guangdong pilot data starts in March 2014 and the Hubei pilot starts from April 2014. 